\title{
An evaluation of the performance of vertical mixing parameterizations for tidal mixing in the Regional Ocean Modeling System (ROMS)
}

Robin Robertson ${ }^{1,2^{*}}$ (I) and Changming Dong ${ }^{2,3}$

\begin{abstract}
Vertical mixing is important in the ocean for maintaining its stratification, redistributing temperature and salinity, distributing nutrients and pollutants, and the energy cascade. It plays a key role in ocean energy transport, climate change, and marine ecosystems. Getting the mixing right in ocean circulation and climate models is critical in reproducing ocean and climate physics. Ocean models, like the Regional Ocean Modeling System (Rutgers ROMS 3.4), provide several options for determining vertical mixing through the vertical mixing parameterization schemes. To evaluate which of these methods best reproduces realistic vertical mixing by internal tides, simulations of baroclinic tides generated by a seamount were performed using seven different vertical mixing parameterizations: Mellor-Yamada 2.5 (MY), Large-McWilliams-Doney's Kpp (LMD), Nakanishi-Niino's modification of Mellor-Yamada (NN), and four versions of Generic Length Scale (GLS). The GLS versions in ROMS 3.4 severely overmixed the water column within a day and were not considered realistic. We suspect that a coding error has been introduced for it. We focused on the performance of the MY, LMD, and NN vertical mixing parameterizations. LMD was found to overmix the water column. The performance of MY and NN were nearly equivalent and both well reproduced the observed velocity and diffusivity fields. NN performed slightly better by having a lower rms for $\mathrm{M}_{2}$ and $\mathrm{K}_{1}$, less benthic mixing, more mid-water column mixing, less overmixing, and fewer extremely high diffusivities $\left(>1 \mathrm{~m}^{2} \mathrm{~s}^{-1}\right)$.
\end{abstract}

Keywords: Vertical mixing, Mixing parameterizations, Tides, Sigma-coordinate models, Seamount

\section{Introduction}

Vertical ocean mixing is an important physical process in the ocean. It maintains the temperature and salinity stratification, drives the global overturning circulation (Munk and Wunsch 1998), redistributes nutrients and larvae for biological productivity and fisheries, distributes heat and salt, and influences climate dynamics. Due to the wide range of processes and scales, mixing is very difficult to represent in climate and ocean circulation models. This results in mixing being one of the most significant, present shortcomings of these models. Vertical mixing is generally caused by turbulence, which Feynmann considered one of the greatest challenges of physics and one

\footnotetext{
*Correspondence: robin.robertson@xmu.edu.my

${ }^{1}$ China-ASEAN College of Marine Sciences, Xiamen University Malaysia, Jalan Sunsuria, Bandar Sunsuria, 43900 Sepang, Selangor, Malaysia

Full list of author information is available at the end of the article
}

of the "most important unsolved problems of classical physics" (Feynmann and Leighton 1994). The difficulty is that there are many processes that cause turbulence and mixing, from wind and tides to vertical migration of zooplankton. These processes cover a wide range of scales from hundreds of kilometers to centimeters.

Around 20 processes are considered to be significant contributors to vertical mixing in the ocean (Garrett 2003); however, a few sources dominate. These forces are depth dependent, with the wind being the most important in the upper ocean. However, deeper in the ocean, tides and internal tides, and interactions of flow with topography including lee waves and flow over sills dominate (Kunze et al. 2006). Additionally, some consider biological mixing to be a key player (Kunze et al. 2006). A significant amount of vertical mixing, $\sim 2 \mathrm{TW}$ $\left(1 \mathrm{TW}=10^{12} \mathrm{~W}\right)$, has been attributed to tides (Munk and Wunsch 1998; Egbert and Ray 2000). Roughly half of 
this is estimated to result from mixing by internal tides, generated through interactions of the barotropic tide with topography. Interactions of geostrophic currents or eddies with topography can also generate lee waves, which are estimated to contribute an additional $0.2 \mathrm{TW}$ (Nikurashin and Ferrari 2011). Because of these topographic interactions with tides and/or currents, mixing has been found to occur in specific "hot" spots near topographic features (Garrett 2003). Mixing in these "hot" spots has been observed to be a hundred times higher (Polzin et al. 1997; Naveira-Garabato et al. 2004; KochLarrouy et al. 2015) than background values (Ledwell et al. 1998) with high mid-water column values observed to be localized at specific depths related to the propagation of internal tides. Additionally, mixing varies in time, e.g., tidal mixing follows the spring-neap and daily tidal cycles and wind mixing increases during storms.

Many mixing processes occur at scales smaller than the model resolution; consequently, they cannot be directly simulated, but are represented in the models by sub-grid scale parameterizations. There are basically two types of these parameterizations. The first type represents tidal mixing when tides are not included in the model, such as St. Laurent et al. (2002), and Ijichi and Hibiya (2015). The second type parameterizes the vertical mixing when tides are included in the model, with most of these based on the gradient Richardson number. The latter type is the focus of this study and there are several of these parameterizations presently being used for vertical mixing. The most common ones of the second type are the MellorYamada 2.5 level turbulence closure scheme (MY) (Mellor and Yamada 1982), the Large-McWilliams-Doney Kpp scheme (LMD) (Large and Gent 1999), and the Generic Length Scale scheme (GLS) of Umlauf and Buchard (2003), Umlauf et al. 2003). The GLS scheme has the flexibility to apply several different parameterizations, each associated with a different length scale. The most common length-scale options are $\mathrm{k}-\mathrm{kl}, \mathrm{k}-\omega, \mathrm{\kappa}-\varepsilon$, and generic parameters. A new vertical mixing scheme developed for the atmosphere by Nakanishi and Niino (NN) (2009) has been applied to the ocean to better represent surface mixing and the surface mixed layer (Furuichi and Hibiya 2015). It is based on the MY scheme, but is enhanced to include buoyancy effects on the pressure conversion and implement an alternative stability factor for the turbulent length scale. It was first developed for the convective atmospheric boundary layer (Nakanishi and Niino 2009) and applied to the ocean by Furuichi et al. (2012). Furuichi and Hibiya (2015) found it reproduced mixing intensity better than MY, reducing the warm surface temperature bias generated by that scheme. Robertson implemented the NN scheme in ROMS (Robertson and Hartlipp 2017).
Another scheme has been developed by Klymak and Legg (2010) for the MITgcm model specifically for tidal mixing near steep topography in the deep ocean. Klymak and Legg resolved the overturns and presented a vertical mixing parameterization based on the resolved overturns at the Ozmidov scale. Their scheme requires a vertical resolution on the scale of $5 \mathrm{~m}$. A regional simulation at this scale was performed with the MITgcm by Nagai and Hibiya (2015) for the Indonesian seas with a uniform vertical diffusivity, but not with a vertical diffusivity dependent on overturns, as they believe that the overturns are resolved at this vertical resolution. It has not been included in this study for four reasons: (1) it is specific for the deep ocean and not applicable to shallow water, (2) it requires extremely high vertical resolution $(\sim 10 \mathrm{~m})$, which has high computational cost and is only viable for the smallest domains, (3) this high resolution is more difficult to satisfy over the entire domain in a sigma coordinate model with the vertical resolution dependent on water depth than a z-level model, (4) we were looking at a scenario which was typical for most ROMS simulations, which typically use one-fifth to one-twentieth of the levels required for this scheme, and (5) it is not implemented in ROMS.

Many groups are using ROMS to simulate tidal mixing, which makes it crucial to having vertical mixing well represented in the model (i.e., Petruncio 1996; Holloway and Merrifield 1999; Merrifield and Holloway 2002; Durski et al. 2004; Li et al. 2005; Robertson 2005). There are several important questions concerning these schemes. First, which one of these vertical mixing parameterizations best reproduces mixing in the ocean? Second, how well do these schemes replicate the wide range of spatial and temporal scales and the variability of the ocean processes causing mixing? Additionally, some schemes are likely to represent some specific processes better than others due to how they were developed, which brings up two additional questions:

- Which scheme best simulates wind, tide, benthic, or other ocean mixing processes?

- Which processes are ignored by the different schemes?

Some effort has been made to determine the best mixing scheme for different mixing processes. The MY and LMD schemes in the Regional Ocean Modeling System (ROMS) were compared for wind mixing by Durski et al. (2004) with the result that the performance depended on the stratification strength. MY mixed deeper than LMD when a strong pycnocline was present, but shallower when the pycnocline was weak. In another study, Li et al. (2005) found little difference 
between the results for four vertical mixing parameterizations (MY, LMD, GLS: $\kappa-\omega$, and GLS: $\kappa-\varepsilon$ ) for ROMS simulations in the shallow waters of The Chesapeake Bay. Timmerman and Beckmann (2004) investigated the performance of four different parameterizations of vertical mixing in the Bremerhaven Regional Ice Ocean System (BRIOS) model (sigma coordinates) and found that both MY and LMD overestimated wind mixing, which induced unreasonably strong deep convection. Wind mixing was also evaluated for ROMS at high vertical resolution with four parameterizations (MY, LMD, GLS: generic, and NN) for different locations by Robertson and Hartlipp (2017; hereafter RH17). LMD was found to overmix the upper ocean. None of the schemes reproduced the observed diffusivities well, particularly the high-frequency fluctuations in the observations; however, the best performers were $\mathrm{NN}$ and MY. Warner et al. (2005) focused his vertical mixing parameterization evaluation on four GLS schemes, but included several types of flows: steady barotropic, wind-induced surface mixing, oscillating pressuregradient-driven flow in a stratified fluid, and an estuary case. They were unable to determine which performed the best; however, all performed poorly in the estuary. Tidal mixing was investigated by Robertson (2006, hereafter R06) for nine different vertical mixing parameterizations in ROMS as part of a sensitivity study on a range of different operational parameters for ROMS. Differences in the tidal fields and velocity fields were minor; however, the vertical diffusivity fields generated by the model were widely different and this resulted in differences in the tracer fields (temperature and salinity) with time. Below $2500 \mathrm{~m}$, LMD had extremely high values $\left(>10^{-3} \mathrm{~m}^{2} \mathrm{~s}^{-1}\right)$, which were unrealistic in this region of low velocities and shear. Despite the low shear in this region, the low stratification induced a low gradient Richardson number, generating high diffusivities in the LMD parameterization. The best performers in R06 were found to be MY and three of the GLS schemes $(\kappa-\omega, \kappa-\varepsilon$, and generic). NN was not evaluated in R06, because it was still unknown. From these evaluations, there is no clear best performer out of these schemes, although NN and MY appear to be the leaders.

Another issue for the ROMS model is spurious diapycnal mixing resulting from higher order diffusive advection schemes (Marchesiello et al. 2009). They found that the errors were resolution dependent and were not reduced to an "acceptable" level unless the horizontal resolution was less than $1 \mathrm{~km}$. They developed a new higher order diffusive advective scheme for ROMS, third-order upwind advection, to address this issue.

Two of the aforementioned questions are addressed in this study for tidal mixing using ROMS:
- Which one of these vertical mixing parameterizations best reproduces tidal mixing in the ocean?

- Do the schemes replicate the spatial and temporal variabilities of the ocean processes?

After R06, a new version of the ROMS model was released and a repeat of the vertical mixing evaluation gave different results. These new results are given in "Results" section, after the model and observations are described in "Materials and methods" section and internal wave theory is outlined in "Internal wave theory" section. The new results are more extensively investigated, particularly concerning the temporal behavior of the vertical diffusivity. "Discussion" section discusses the new results and the conclusions are given in "Summary" section.

\section{Materials and methods}

Both the Rutgers version 3.4 ROMS model and observations are used in this study. Since this study is an extension of R06, only brief explanations of the model and the observations, focusing on the changes, are given here. The reader is referred to R06 for a more extensive explanation of both.

Tidal simulations were performed with the only difference between them being the vertical mixing parameterization. Seven vertical mixing parameterizations were investigated: MY, LMD, NN, and four versions of GLS $(\kappa-\kappa l, \kappa-\omega, \kappa-\varepsilon$, and generic). Short descriptions of each appear in Additional file 1: Appendix A. MY, LMD, and GLS are more fully described in R06, and the reader is referred there for more information on them. $\mathrm{NN}$ is fully described in Nakanishi and Niino (2009) and Furuichi and Hibiya (2015) and its implementation in ROMS by the lead author in RH17. An additional simulation was made using only the background diffusivity. This latter simulation was performed to identify spurious mixing due to advection as described by Marchesiello et al. (2009).

The tidal simulations used the Rutgers version of ROMS 3.4 (Shchepetkin and McWilliams 2004) with four major tidal constituents (two semi-diurnals, $\mathrm{M}_{2}$ and $\mathrm{S}_{2}$, and two diurnals, $\mathrm{K}_{1}$ and $\mathrm{O}_{1}$ ). Tidal forcing was implemented by setting elevations and depth-independent velocities along all the open boundaries on the 2-D mode time steps, with the coefficients taken from TPXO8.0 (Egbert and Erofeeva 2002). This is a slight modification from the standard ROMS, which forces on the 3-D mode time steps. This modification has been fully explained in RH17 and Robertson et al. (2017). Both observational and model data were analyzed for tides using Pawlow$i c z$ et al.s T_Tide software package and various Matlab ${ }^{\circledR}$ scripts. There was no wind or net solar forcing. The 
fourth-order Akima advection scheme was used for both horizontal and vertical advection of momentum and tracers.

The domain was Fieberling Guyot $\left(32^{\circ} 26.40^{\circ} \mathrm{N}, 127^{\circ}\right.$ $45.60^{\circ} \mathrm{W}$ ) at $\sim 32^{\circ} \mathrm{N}$ in the eastern Pacific Ocean (a guyot is a volcanic seamount with a flat top with the peak over

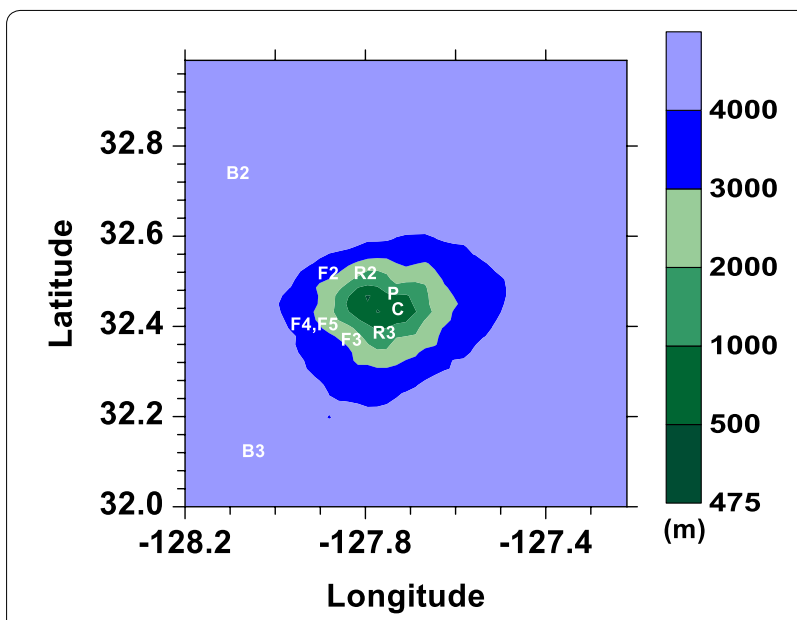

Fig. 1 The bathymetry of Fieberling Guyot with the locations of nine moorings indicated by B2, B3, F2, F3, F4, R2, R3, P, and C
$200 \mathrm{~m}$ below the ocean surface). Simulations were performed for 35 days with the last 30 days of hourly data used for analysis (all hourly data were saved). Prior investigations showed that tidal fields stabilize at midlatitudes, such as this location, within 5 days (R06). The topography and bathymetry are fully described in R06. The horizontal resolution was $2 \mathrm{~km}$ and 60 vertical levels were used.

Observational data, including ADCP data, CTD profiles, and microstructure profiles, were collected over Fieberling Guyot by Brink, Eriksen, Toole, and Kunze (Brink 1991, 1995; Eriksen 1991, 1998; Kunze and Toole 1995, 1997; Toole et al. 1997). They deployed and recovered a set of eight moorings (B2, B3, F2, F3, F4, R2, R3, and $\mathrm{C}$ ) with an additional preliminary mooring over the peak of the guyot (P) (Fig. 1). The mooring data are fully described in R06 and their observational papers (Brink 1991, 1995; Eriksen 1991, 1998; Kunze and Toole 1995, 1997; Toole et al. 1997). Moorings F3 and F4 were very close together, so only F3 was used.

\section{Internal wave theory}

Many different types of internal waves exist and some of them depend on latitude for their generation and propagation. Linear internal wave theory is very well developed

Table 1 The dispersion relations and group speeds for a variety of barotropic and baroclinic waves

\begin{tabular}{|c|c|c|}
\hline Wave type & Dispersion & Horizontal group speed \\
\hline Two-layer interfacial wave: $\infty$ over $\infty$ & $\omega=\sqrt{\frac{\left(\rho_{2}-\rho_{1}\right)}{\left(\rho_{1}+\rho_{2}\right)} g k}$ & $c_{g}=\frac{1}{2} \sqrt{\frac{\left(\rho_{2}-\rho_{1}\right)}{\left(\rho_{1}+\rho_{2}\right)} \frac{g}{k}}$ \\
\hline Two-layer interfacial wave: finite over $\infty$ : barotropic & $\omega=\sqrt{g k}$ & $c_{g}=\frac{1}{2} \sqrt{\frac{g}{k}}$ \\
\hline Two-layer interfacial wave: finite over $\infty$ : baroclinic shallow water & $\begin{array}{l}\omega=\sqrt{g^{\prime} H k} \\
g^{\prime}=g\left(\frac{\rho_{2}-\rho_{1}}{\rho_{2}}\right)\end{array}$ & $c_{g}=\sqrt{g^{\prime} H}$ \\
\hline Continuous stratification without rotation & $\omega=N \sqrt{\frac{k^{2}+l^{2}}{k^{2}+l^{2}+m^{2}}}=N \cos \theta$ & $c_{g x}=N m^{2}\left(k^{2}+m^{2}\right)^{-3 / 2}$ \\
\hline Continuous stratification with rotation & $\omega_{j}^{2}=\frac{f^{2} m_{j}^{2}+N^{2} k^{2}}{k^{2}+m_{j}^{2}}$ & $c_{g j}=\frac{k m_{j}^{2}\left(N^{2}-f^{2}\right)}{\left(f^{2} m_{j}^{2}+N^{2} k^{2}\right)^{1 / 2}\left(k^{2}+m_{j}^{2}\right)^{3 / 2}}$ \\
\hline Barotropic Kelvin wave & $\omega=\sqrt{g H} k$ & $c_{g x}=\sqrt{g H}$ \\
\hline Baroclinic Kelvin wave & $\omega=\sqrt{g^{\prime} H} k$ & $c_{g x}=\sqrt{g^{\prime} H}$ \\
\hline Barotropic Poincaré wave & $\omega=\sqrt{f^{2}+g H\left(k^{2}+l^{2}\right)}$ & $C_{g x}=\frac{g H k}{\sqrt{f^{2}+g H k^{2}}}$ \\
\hline Baroclinic Poincaré wave & $\begin{array}{l}\omega=\sqrt{f^{2}+c^{2}\left(k^{2}+l^{2}\right)} \\
c=\sqrt{g^{\prime} H} \text { or } c=N / m=N H / j \pi\end{array}$ & $c_{g x}=\frac{c^{2} k}{\sqrt{f^{2}+c^{2} k^{2}}}$ \\
\hline Shallow water surface gravity wave & $\omega=\sqrt{g H} k$ & $c_{g x}=\sqrt{g H}$ \\
\hline Deep water surface gravity wave & $\omega=\sqrt{g k}$ & $c_{g}=\frac{1}{2} \sqrt{\frac{g}{k}}$ \\
\hline
\end{tabular}

$\omega$ is the frequency, $k$ and $I$ are the horizontal wavenumbers $\left(I=0\right.$, wave propagation aligned in $x$-direction), $m$ is the vertical wave number, and $c_{\mathrm{g}}$ the horizontal group speed. The water depth is $H$ and the upper layer thickness is $H_{U}$. Gravity is $g$ and the reduced gravity is $g^{\prime} . \rho_{1}$ and $\rho_{2}$ are the densities of the upper and lower layers, respectively. $N$ is the Brunt-Väisäla frequency and $f$ is the inertial frequency for the latitude. The mode number is represented by $j$. The equations were taken from Kundu et al. (2015) 
Table 2 The horizontal wavenumber, wavelength, and group speed for the $M_{2}$ constituent (period=12.42 h; $\omega=1.405 \times 10^{-4} \mathrm{~s}^{-1}$ ) in a water depth of $500 \mathrm{~m}$ and an upper layer thickness of $200 \mathrm{~m}$ at $32.5^{\circ} \mathrm{N}$, following the equations in Table 1

\begin{tabular}{|c|c|c|c|c|}
\hline Wave type & Mode & $k\left(\mathrm{~m}^{-1}\right)$ & $\lambda_{\mathrm{H}}(\mathrm{km})$ & $c_{g}\left(\mathrm{~m} \mathrm{~s}^{-1}\right)$ \\
\hline Two-layer interfacial wave: $\infty$ over $\infty$ & - & $1.6 \times 10^{-6}$ & 618 & 43 \\
\hline Two-layer interfacial wave: finite over $\infty$ : barotropic & - & $2.0 \times 10^{-9} 9$ & 490,000 & 34,900 \\
\hline Two-layer interfacial wave: finite over $\infty$ : baroclinic shallow water & - & $6.4 \times 10^{-5}$ & 16 & 2.2 \\
\hline \multirow[t]{2}{*}{ Continuous stratification without rotation } & 1 & $5.7 \times 10^{-5}$ & 18 & 2.5 \\
\hline & 2 & $1.1 \times 10^{-4}$ & 9 & 1.2 \\
\hline \multirow[t]{2}{*}{ Continuous stratification with rotation } & 1 & $4.7 \times 10^{-5}$ & 21 & 2.1 \\
\hline & 2 & $9.4 \times 10^{-5}$ & 11 & 1.0 \\
\hline Barotropic Kelvin wave & - & $2.0 \times 10^{-6}$ & 498 & 70 \\
\hline Baroclinic Kelvin wave & - & $6.3 \times 10^{-5}$ & 16 & 2.2 \\
\hline Barotropic Poincaré wave & - & $1.7 \times 10^{-6}$ & 600 & 58 \\
\hline \multirow[t]{2}{*}{ Baroclinic Poincaré wave } & 1 & $4.7 \times 10^{-5}$ & 21 & 2.1 \\
\hline & 2 & $9.4 \times 10^{-5}$ & 11 & 1.0 \\
\hline Shallow water surface gravity wave & - & $2.0 \times 10^{-6}$ & 498 & 70 \\
\hline Deep water surface gravity wave & - & $2.1 \times 10^{-} 9$ & 496,000 & 34,900 \\
\hline
\end{tabular}

The mode 1 wavelength is $1000 \mathrm{~m}$ and the mode 2 is $500 \mathrm{~m}$. Italics numbers indicate wavelengths that are resolvable in the simulations. Unrealistic waves due to wavelengths exceeding Earth's circumference have been struck through

(Kundu et al. 2015). Following internal wave equations, the horizontal wavenumber, horizontal wavelength, and group speed were calculated for different barotropic and mode 1 and mode 2 baroclinic waves and for surface waves according to the relations in Table 1 . The values for $\mathrm{M}_{2}$ were calculated with a water depth of $500 \mathrm{~m}$ and the latitude of Fieberling Guyot, and are presented in
Table 2. This depth was chosen as the water depth where the peak $\mathrm{M}_{2}$ response occurred. The values were also calculated for $K_{1}$; however, the water depth of its maximum response $(1200 \mathrm{~m})$ was used and it was calculated for both $32.5^{\circ} \mathrm{N}$, the actual latitude (Table 3), and for a latitude slightly equatorward of the $K_{1}$ critical latitude, $29.5^{\circ} \mathrm{N}$ (Table 4). The critical latitude is defined as the

Table 3 The horizontal wavenumber, wavelength, and group speed for the $K_{1}$ constituent (period $=23.94 h$; $\omega=7.29 \times 10^{-5} \mathrm{~s}^{-1}$ ) in a water depth of $1200 \mathrm{~m}$ and an upper layer thickness of $200 \mathrm{~m}$ at $32.5^{\circ} \mathrm{N}$, following the equations in Table 1

\begin{tabular}{|c|c|c|c|c|}
\hline Wave type & Mode & $k\left(\mathrm{~m}^{-1}\right)$ & $\lambda_{\mathrm{H}}(\mathrm{km})$ & $c_{g}\left(\mathrm{~m} \mathrm{~s}^{-1}\right)$ \\
\hline Two-layer interfacial wave: $\infty$ over $\infty$ & - & $4.4 \times 10^{-7}$ & 2300 & 84 \\
\hline Two-layer interfacial wave: finite over $\infty$ : barotropic & - & $5.4 \times 1 \theta^{-10}$ & $1,800,000$ & 67,000 \\
\hline $\begin{array}{l}\text { Two-layer interfacial wave: finite over } \infty \text { : baroclinic shallow } \\
\text { water }\end{array}$ & - & $3.3 \times 10^{-5}$ & 30 & 2.2 \\
\hline \multirow[t]{2}{*}{ Continuous stratification without rotation } & 1 & $2.9 \times 10^{-5}$ & 34 & 2.5 \\
\hline & 2 & $5.8 \times 10^{-5}$ & 17 & 1.2 \\
\hline \multirow[t]{2}{*}{ Continuous stratification with rotation } & 1 & $\infty$ & $\infty$ & $\infty$ \\
\hline & 2 & $\infty$ & $\infty$ & $\infty$ \\
\hline Barotropic Kelvin wave & - & $1.0 \times 10^{-6}$ & 960 & 70 \\
\hline Baroclinic Kelvin wave & - & $3.3 \times 10^{-5}$ & 30 & 2.2 \\
\hline Barotropic Poincaré wave & - & $\infty$ & $\infty$ & $\infty$ \\
\hline \multirow[t]{2}{*}{ Baroclinic Poincaré wave } & 1 & $\infty$ & $\infty$ & $\infty$ \\
\hline & 2 & $\infty$ & $\infty$ & $\infty$ \\
\hline Shallow water surface gravity wave & - & $1.0 \times 10^{-6}$ & 960 & 70 \\
\hline Deep water surface gravity wave & - & $5.4 \times 10^{-10}$ & $1,800,000$ & 67,000 \\
\hline
\end{tabular}

The mode 1 wavelength is $2400 \mathrm{~m}$ and the mode 2 is $1200 \mathrm{~m}$. Italics numbers indicate wavelengths that are resolvable in the simulations. Unrealistic waves due to wavelengths exceeding Earth's circumference have been struck through 
Table 4 The horizontal wavenumber, wavelength, and group speed for the $K_{1}$ constituent (period=23.94 $h$; $\omega=7.29 \times 10^{-5} \mathrm{~s}^{-1}$ ) in a water depth of $1200 \mathrm{~m}$ and an upper layer thickness of $200 \mathrm{~m}$ at $29.5^{\circ} \mathrm{N}$, following the equations in Table 1

\begin{tabular}{|c|c|c|c|c|}
\hline Wave type & Mode & $k\left(\mathrm{~m}^{-1}\right)$ & $\lambda_{\mathrm{H}}(\mathrm{km})$ & $c_{g}\left(\mathrm{~m} \mathrm{~s}^{-1}\right)$ \\
\hline Two-layer interfacial wave: $\infty$ over $\infty$ & - & $4.4 \times 10^{-7}$ & 2300 & 84 \\
\hline Two-layer interfacial wave: finite over $\infty$ : barotropic & - & $5.4 \times 10^{-}+10$ & $7,800,000$ & 67,000 \\
\hline $\begin{array}{l}\text { Two-layer interfacial wave: finite over } \infty \text { : baroclinic shallow } \\
\text { water }\end{array}$ & - & $3.3 \times 10^{-5}$ & 30 & 2.2 \\
\hline \multirow[t]{2}{*}{ Continuous stratification without rotation } & 1 & $2.9 \times 10^{-5}$ & 34 & 2.4 \\
\hline & 2 & $5.8 \times 10^{-5}$ & 17 & 1.2 \\
\hline \multirow[t]{2}{*}{ Continuous stratification with rotation } & 1 & $5.0 \times 10^{-6}$ & 197 & 1.5 \\
\hline & 2 & $1.0 \times 10^{-5}$ & 99 & 0.2 \\
\hline Barotropic Kelvin wave & - & $1.0 \times 10^{-6}$ & 960 & 70 \\
\hline Baroclinic Kelvin wave & - & $3.3 \times 10^{-5}$ & 30 & 2.2 \\
\hline Barotropic Poincaré wave & - & $1.8 \times 10^{-7}$ & 5600 & 12 \\
\hline \multirow[t]{2}{*}{ Baroclinic Poincaré wave } & 1 & $5.0 \times 10^{-6}$ & 198 & 0.4 \\
\hline & 2 & $1.0 \times 10^{-5}$ & 99 & 0.2 \\
\hline Shallow water surface gravity wave & - & $1.0 \times 10^{-6}$ & 960 & 70 \\
\hline Deep water surface gravity wave & - & $5.4 \times 10^{-}+10$ & $1,800,000$ & 67,000 \\
\hline
\end{tabular}

The mode 1 wavelength is $2400 \mathrm{~m}$ and the mode 2 is $1200 \mathrm{~m}$. Italic numbers indicate wavelengths that are resolvable in the simulations. Unrealistic waves due to wavelengths exceeding Earth's circumference have been struck through

latitude where the inertial frequency equals the tidal frequency, which for $\mathrm{K}_{1}$ is $30.0^{\circ} \mathrm{N}$ or $\mathrm{S}$ and for $\mathrm{O}_{1}$ is $27.6^{\circ} \mathrm{N}$ or S. In these tables, the horizontal wavelength is in italics if the horizontal wavelength is resolved (greater than $4 \mathrm{~km}$ for the model resolution of $2 \mathrm{~km}$ and less than the domain width, $\sim 120 \mathrm{~km}$ ). For reference, the Pacific Basin is $\sim 12,000 \mathrm{~km}$ wide and the theoretical wavelength for some waves exceeds the basin width. In these tables, the numbers are stricken through if the wavelength is unrealistic on Earth The horizontal wavenumber, wavelength, and group speed were also calculated for the $4 \mathrm{cpd}$ and 6 cpd harmonics (Tables 5 and 6, respectively) and for the $\mathrm{S}_{2}$ and $\mathrm{O}_{1}$ constituents (Additional file 1: Tables S1, S2, respectively). The harmonics are of interest, not only due to overtides, but also to investigate the cascade of energy from the tides to the harmonics and higher frequencies.

Table 5 The horizontal wavenumber, wavelength, and group speed for a frequency of $4 \mathrm{cpd}$ (period=6 h; $\omega=2.91 \times 10^{-4} \mathrm{~s}^{-1}$ ) in a water depth of $500 \mathrm{~m}$ and an upper layer thickness of $200 \mathrm{~m}$ at $32.5^{\circ} \mathrm{N}$, following the equations in Table 1

\begin{tabular}{|c|c|c|c|c|}
\hline Wave type & Mode & $k\left(\mathrm{~m}^{-1}\right)$ & $\lambda_{\mathrm{H}}(\mathrm{km})$ & $c_{g}\left(\mathrm{~m} \mathrm{~s}^{-1}\right)$ \\
\hline Two-layer interfacial wave: $\infty$ over $\infty$ & - & $6.9 \times 10^{-6}$ & 144 & 21 \\
\hline Two-layer interfacial wave: finite over $\infty$ : barotropic & - & $8.6 \times 10^{-9}$ & 120,000 & 17,000 \\
\hline Two-layer interfacial wave: finite over $\infty$ : baroclinic shallow water & - & $1.3 \times 10^{-4}$ & 7.6 & 2.2 \\
\hline \multirow[t]{2}{*}{ Continuous stratification without rotation } & 1 & $1.2 \times 10^{-4}$ & 8.5 & 2.5 \\
\hline & 2 & $2.3 \times 10^{-4}$ & 4.3 & 1.2 \\
\hline \multirow[t]{2}{*}{ Continuous stratification with rotation } & 1 & $1.1 \times 10^{-4}$ & 8.8 & 2.4 \\
\hline & 2 & $2.2 \times 10^{-4}$ & 4.4 & 1.2 \\
\hline Barotropic Kelvin wave & - & $4.2 \times 10^{-6}$ & 240 & 70 \\
\hline Baroclinic Kelvin wave & - & $1.3 \times 10^{-4}$ & 7.5 & 2.2 \\
\hline Barotropic Poincaré wave & - & $4.0 \times 10^{-6}$ & 250 & 67 \\
\hline \multirow[t]{2}{*}{ Baroclinic Poincaré wave } & 1 & $1.1 \times 10^{-4}$ & 8.9 & 2.4 \\
\hline & 2 & $2.3 \times 10^{-4}$ & 4.4 & 1.2 \\
\hline Shallow water surface gravity wave & - & $4.2 \times 10^{-6}$ & 240 & 70 \\
\hline Deep water surface gravity wave & - & $8.6 \times 10^{-9}$ & 120,000 & 17,000 \\
\hline
\end{tabular}

The mode 1 wavelength is $1000 \mathrm{~m}$ and the mode 2 is $500 \mathrm{~m}$. Italic numbers indicate wavelengths that are resolvable in the simulations Unrealistic waves due to wavelengths exceeding Earth's circumference have been struck through 
Table 6 The horizontal wavenumber, wavelength, and group speed for a frequency of 6 cpd (period $=4$ h; $\omega=4.36 \times 10^{-4} \times \mathrm{s}^{-1}$ ) in a water depth of $500 \mathrm{~m}$ and an upper layer thickness of $200 \mathrm{~m}$ at $32.5^{\circ} \mathrm{N}$, following the equations in Table 1

\begin{tabular}{|c|c|c|c|c|}
\hline Wave type & Mode & $k\left(\mathrm{~m}^{-1}\right)$ & $\lambda_{\mathbf{H}}(\mathrm{km})$ & $c_{g}\left(\mathrm{~m} \mathrm{~s}^{-1}\right)$ \\
\hline Two-layer interfacial wave: $\infty$ over $\infty$ & - & $1.6 \times 10^{-5}$ & 64 & 14 \\
\hline Two-layer interfacial wave: finite over $\infty$ : barotropic & - & $1.9 \times 10^{-8}$ & 51,000 & 11,000 \\
\hline Two-layer interfacial wave: finite over $\infty$ : baroclinic shallow water & - & $2.0 \times 10^{-4}$ & 5.0 & 2.2 \\
\hline \multirow[t]{2}{*}{ Continuous stratification without rotation } & 1 & $1.8 \times 10^{-4}$ & 5.7 & 2.5 \\
\hline & 2 & $3.5 \times 10^{-4}$ & 2.8 & 1.2 \\
\hline \multirow[t]{2}{*}{ Continuous stratification with rotation } & 1 & $1.7 \times 10^{-4}$ & 5.8 & 2.4 \\
\hline & 2 & $3.4 \times 10^{-4}$ & 2.9 & 1.2 \\
\hline Barotropic Kelvin wave & - & $6.2 \times 10^{-6}$ & 160 & 70 \\
\hline Baroclinic Kelvin wave & - & $2.0 \times 10^{-4}$ & 5.1 & 2.2 \\
\hline Barotropic Poincaré wave & - & $6.1 \times 10^{-6}$ & 163 & 69 \\
\hline \multirow[t]{2}{*}{ Baroclinic Poincaré wave } & 1 & $1.7 \times 10^{-4}$ & 5.8 & 2.4 \\
\hline & 2 & $3.5 \times 10^{-4}$ & 2.9 & 1.2 \\
\hline Shallow water surface gravity wave & - & $6.2 \times 10^{-6}$ & 160 & 70 \\
\hline Deep water surface gravity wave & - & $1.9 \times 10^{-8}$ & 51,000 & 11,000 \\
\hline
\end{tabular}

The mode 1 wavelength is $1000 \mathrm{~m}$ and the mode 2 is $500 \mathrm{~m}$. Italic numbers indicate wavelengths that are resolvable in the simulations. Unrealistic waves due to wavelengths exceeding Earth's circumference have been struck through

From these calculations, it is expected that the baroclinic diurnal tides should be trapped for a wave in a continuously stratified ocean with rotation and for Poincaré waves (Table 3). However, at Fieberling Guyot, the tides generated a residual current that shifts the diurnal critical latitude sufficiently equatorward of the seamount to enable diurnal baroclinic tides to propagate (Kunze and Toole 1997). Consequently, the calculations for $K_{1}$ were repeated for $29.5^{\circ}$, which is $0.5^{\circ}$ equatorward of its critical latitude to provide an estimate of the values, corresponding to the critical latitude shift (Table 6).

Calculations were made for 11 different types waves (Table 1); however, the equations are equivalent or nearly equivalent for several pairs:

- Two-layer interfacial wave: finite over $\infty$ : barotropic and deep water surface gravity wave.

- Two-layer interfacial wave: finite over $\infty$ : baroclinic shallow water and baroclinic Kelvin wave.

- Continuous stratification with rotation and baroclinic Poincaré wave.

- Barotropic Kelvin wave and shallow water surface gravity wave.

Furthermore, a quick inspection of Tables 2, 3, 4, 5, 6, and Additional file 1: Tables S1, S2 shows that many of the wavelengths are too large to be resolved in the domain $(\sim 120 \mathrm{~km})$. These waves will not be present in the simulations and some of them, such as deep water surface gravity waves, are not realistic at tidal frequencies.
Wavelengths that can be resolved and can be present in the model results are indicated in Tables 2, 3, 4, 5, 6, and Additional file 1: Tables S1, S2 in italics. At the $\mathrm{M}_{2}$ period, waves likely to be generated in the model of Fieberling Guyot include two-layer baroclinic shallow water waves, mode 1 and 2 continuous stratification both with and without rotation, baroclinic Kelvin waves, and mode 1 and 2 baroclinic Poincaré waves (Table 1). All of these waves propagate at speeds ranging from 1.0 to $2.5 \mathrm{~m} \mathrm{~s}^{-1}$. At the $K_{1}$ period, fewer possibilities exist, with only twolayer baroclinic shallow water waves, mode 1 and 2 continuous stratification without rotation, and baroclinic Kelvin waves (Table 2). Since the Coriolis parameter plays a significant role at tidal scales, continuous stratification without rotation is counter to the physics at these scales. Even if the domain is shifted equatorward of the $K_{1}$ critical latitude where Poincaré waves can propagate, their wavelengths are at the limit or too large for the domain (Table 3 ). All the $K_{1}$ waves also propagate at speeds ranging from 1.0 to $2.5 \mathrm{~m} \mathrm{~s}^{-1}$. This is not surprising, since for many of these waves, group speed is more dependent on water depth, stratification, or the vertical wavenumber than frequency. At a $6 \mathrm{~h}$ period, the same waves can be resolved as for $\mathrm{M}_{2}$ and their group speeds are roughly equivalent (Table 5 ); however, at a $4 \mathrm{~h}$ period, mode 2 waves are too short to be resolved in the model at a $2 \mathrm{~km}$ resolution. With the 6 and $4 \mathrm{~h}$ periods, the wavelengths are appreciably shorter than for the major tidal constituents. 


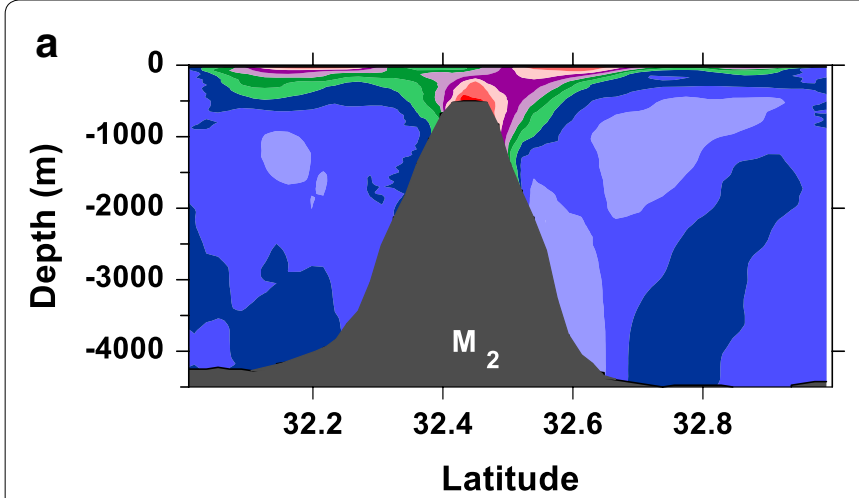

b

Fig. 2 A North-South transect through the domain of the major axes of the tidal ellipse using the baroclinic anomaly velocities for $\mathbf{a} \mathrm{M}_{2}$ and $\mathbf{b} \mathrm{K}_{1}$

\section{Results}

Internal tides at both the diurnal $\left(\mathrm{K}_{1}\right.$ and $\left.\mathrm{O}_{1}\right)$ and semidiurnal $\left(\mathrm{M}_{2}\right.$ and $\left.\mathrm{S}_{2}\right)$ frequencies were present in the upper $1000 \mathrm{~m}$ over the guyot as seen in the major axes of the tidal ellipses for the baroclinic anomalies, which is the difference of the velocity with the vertical mean velocity (Fig. 2). The semidiurnal major axes of the baroclinic anomalies were stronger than those of the diurnal by several $\mathrm{cm} \mathrm{s}^{-1}$. The wavelengths in the model roughly agree with mode 1 internal waves in continuous stratification with rotation for both $\mathrm{M}_{2}$ and $\mathrm{K}_{1}$ (Tables 2 and 3).

The major axes for the diurnal and semidiurnal constituents were compared to those observed at the mooring locations. There was good agreement between the

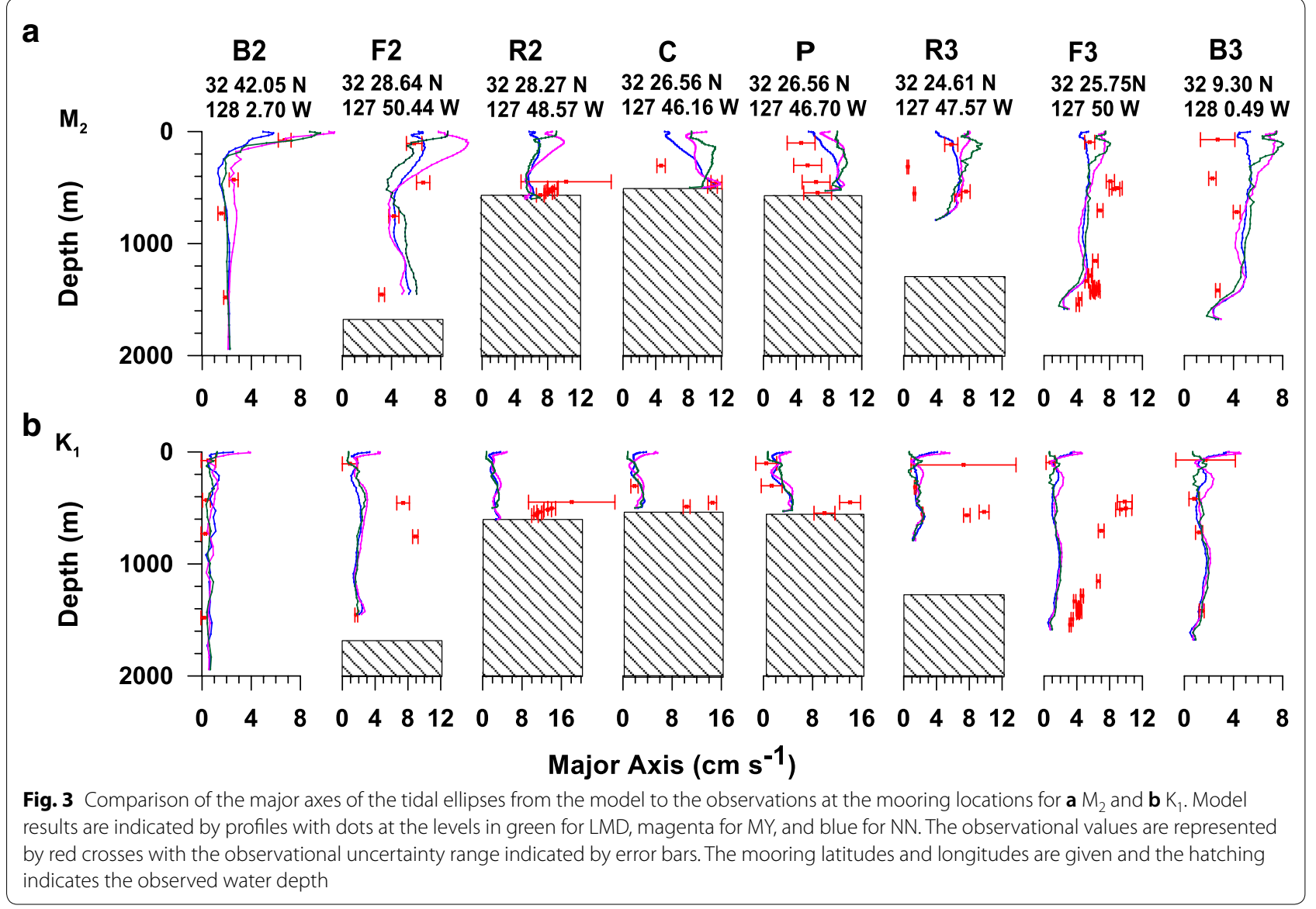


observations and the model results for the $\mathrm{M}_{2}$ constituent, except at R3 where multiple observations existed and the model only matched one set (Fig. 3a). The performance of the different vertical mixing schemes will be evaluated later. Note that the water depth in the model differed by more than $200 \mathrm{~m}$ at F2, R2, F3, and B3. For $K_{1}$, the model agreed well for the background locations B2 and B3 (Fig. 3b), but underestimated the major axes between 400 and $1000 \mathrm{~m}$ depth over the flanks of the guyot (F2 and F3) and the rim (R2 and R3). The mismatch was attributed to a combination of the shift of the diurnal critical latitude and the model resolution, as it was in R06. Over the crest of the guyot, there was good agreement for the mid-water column, but the benthic values were underestimated (Fig. 3b). Again, the discrepancy was attributed to a combination of the horizontal resolution and the critical latitude shift, similar to the study in R06, where the resolution issue is fully discussed.

\section{Effects on the velocities}

Tidal velocities are represented by the major axes of the tidal ellipses. Although, cases with seven different vertical mixing parameterizations were performed, only three are shown in Fig. 4 for the $M_{2}$ and $K_{1}$ constituents (and in Additional file 1: Figures $\mathrm{S} 1$ for the $\mathrm{S}_{2}$ and $\mathrm{O}_{1}$ constituents). The four GLS simulations drastically overmixed and had extremely high diffusivities (three had a mean of $15.7 \mathrm{~m}^{2} \mathrm{~s}^{-1}$ ) (major axes shown in Additional file 1: Figure S2). The water column was essentially barotropic within a day (Additional file 1: Figure S2). It is believed that there is an error in the GLS software routines for ROMS 3.4. (The ROMS group was notified.) Consequently, the
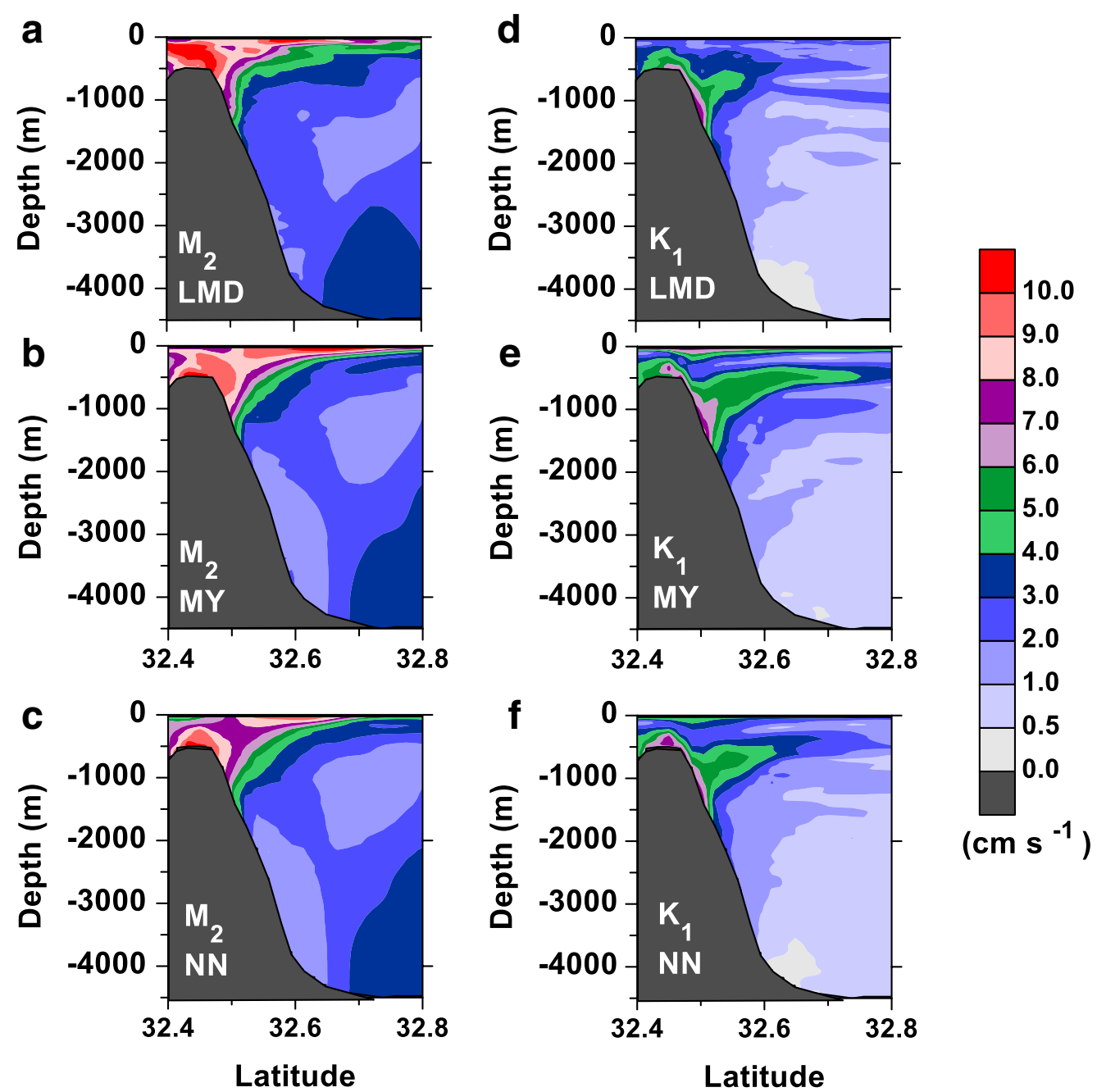

Fig. 4 The major axes of the $\mathbf{a}-\mathbf{c} \mathrm{M}_{2}$ and $\mathbf{d}-\mathbf{f} \mathrm{K}_{1}$ tidal ellipses for the baroclinic anomalies over the guyot from simulations $u$ sing the $\mathbf{a}$, $\mathbf{d} \mathrm{LMD}$, $\mathbf{b}$, e $\mathrm{MY}$, and $\mathbf{c}$, $\mathbf{f} \mathrm{NN}$ vertical mixing parameterizations 
vertical mixing parameterization evaluation focused on the LMD, MY, and NN schemes.

There were only slight differences in the $\mathrm{M}_{2}$ major axes for these three vertical mixing parameterizations, primarily in the upper $1000 \mathrm{~m}$ over the seamount (Fig. 4ac). The differences were also minor for $K_{1}$, although slightly more obvious, with stronger beams propagating further from the guyot with MY (Fig. $4 \mathrm{~d}-\mathrm{f}$ ). The major ellipse fields for $S_{2}$ and $\mathrm{O}_{1}$ were also nearly identical for the different vertical mixing parameterizations, although the beams propagated further for $\mathrm{O}_{1}$ (Additional file 1 : Figure S1). Likewise, spectra of both the east-west and north-south baroclinic anomalies were very similar for the three different vertical mixing parameterizations (shown for location R2 in Fig. 5, and for the other

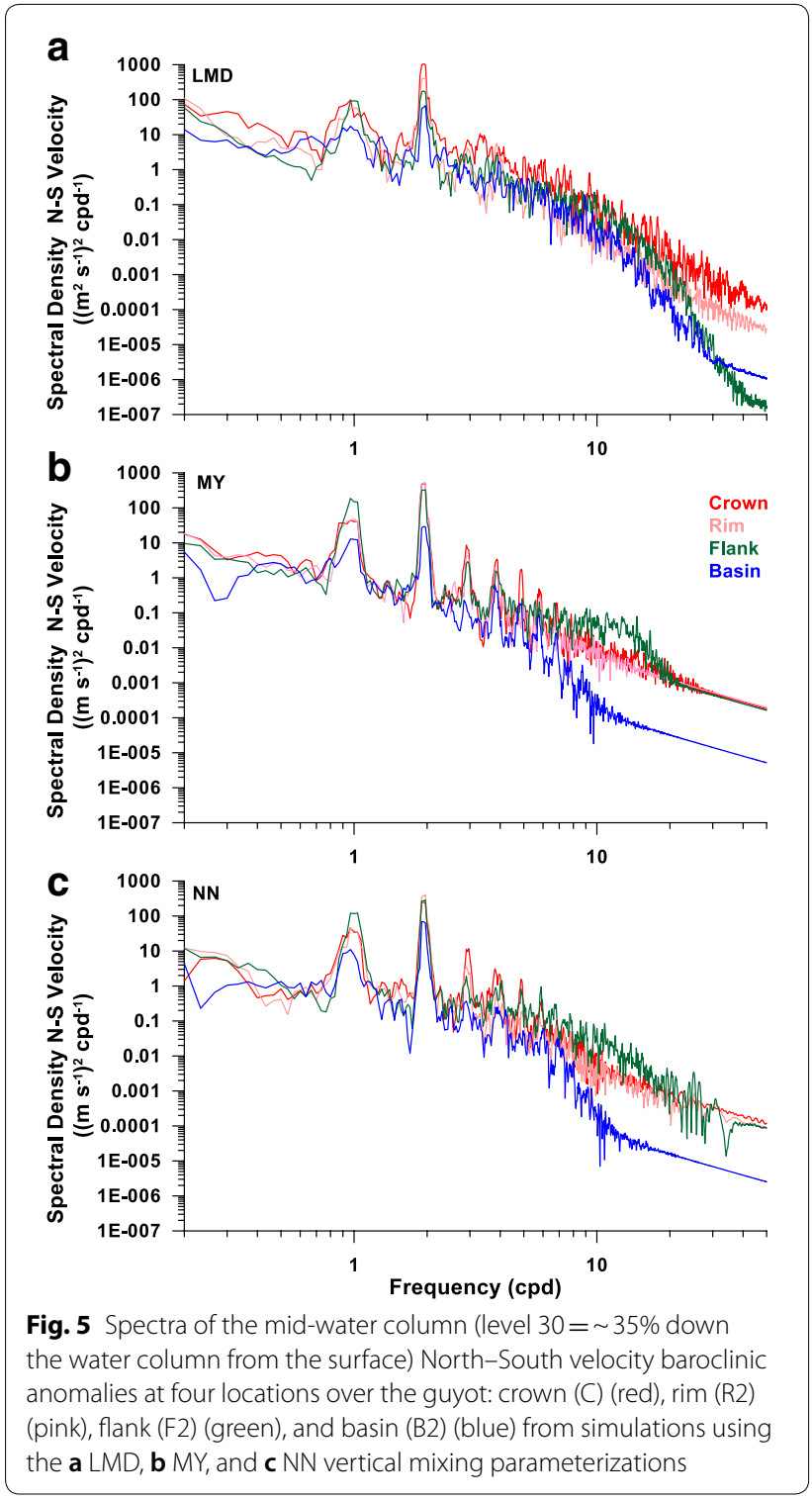

mooring locations in Additional file 1: Figures S3-S7). In the spectra, LMD had a lower, wider peak at the diurnal frequency and generated less energy at the harmonics than MY or NN (Fig. 5a compared to b, c).

Comparison of the performance of the three mixing parameterizations to observations showed that $\mathrm{MY}$ and NN had high energies in $\mathrm{M}_{2}$ at F2 and R2 that were not present in LMD (Fig. 3). MY matched the observations at $\sim 600 \mathrm{~m}$ better, but were worse at $\sim 200 \mathrm{~m}$; thus, a definitive better performance could not be verified. $\mathrm{NN}$ was the opposite and matched at $\sim 200 \mathrm{~m}$, but were underestimated them at $\sim 600 \mathrm{~m}$. RMS differences for the three vertical mixing parameterizations are similar (Table 7). NN has a slightly lower RMS for $\mathrm{M}_{2}$ than the other two schemes, but slightly higher for $\mathrm{S}_{2}$ and $\mathrm{O}_{1}$. Although NN performed slightly better for $\mathrm{M}_{2}$, the velocity fields appeared to be relatively independent of the vertical mixing parameterization.

\section{Effects on the vertical temperature diffusivities}

In contrast to the velocities, the vertical diffusivities of both momentum and temperature varied widely between the different vertical mixing parameterizations (vertical temperature diffusivity shown in Fig. 6). The vertical diffusivities of temperature and momentum behaved similarly, so here only the vertical temperature diffusivities are presented. Comparing the vertical diffusivity of temperature to observations is problematic, since the observations are typically a snapshot and the model results are a time series (Fig. 7). The usual statistical analysis of a mean does not work well, since the vertical mixing parameterization is basically bimodal, with most of the values very low $\left(\sim 10^{-6} \mathrm{~m}^{2} \mathrm{~s}^{-1}\right)$ and a smaller cluster of values spread between much higher values (Fig. 8). To address this issue, a significant vertical diffusivity was defined, as the mean of the highest $1 / 3$ of the values, in a similar manner as surface wave theory.

The significant vertical diffusivity varied by orders of magnitude as seen in both its mean value over the transect and the spatial distribution of values in the water column (Fig. 6). The means of the significant diffusivities were quite high; $43.3 \mathrm{~m}^{2} \mathrm{~s}^{-1}$ for LMD, $0.025 \mathrm{~m}^{2} \mathrm{~s}^{-1}$

Table 7 RMS differences between the model estimates and observations for the major axes of the tidal ellipses for four constituents, $M_{2}, S_{2}, K_{1}$, and $O_{1}$, for the three different vertical mixing parameterizations

\begin{tabular}{lllll}
\hline & $\mathbf{M}_{\mathbf{2}}$ & $\mathbf{S}_{\mathbf{2}}$ & $\mathbf{K}_{\mathbf{1}}$ & $\mathbf{O}_{\mathbf{1}}$ \\
\hline LMD & 2.9 & 1.1 & 5.8 & 2.0 \\
MY & 2.7 & 1.0 & 5.9 & 2.2 \\
NN & 2.5 & 1.2 & 5.8 & 2.3
\end{tabular}

Italic numbers indicate the lowest rms differences 

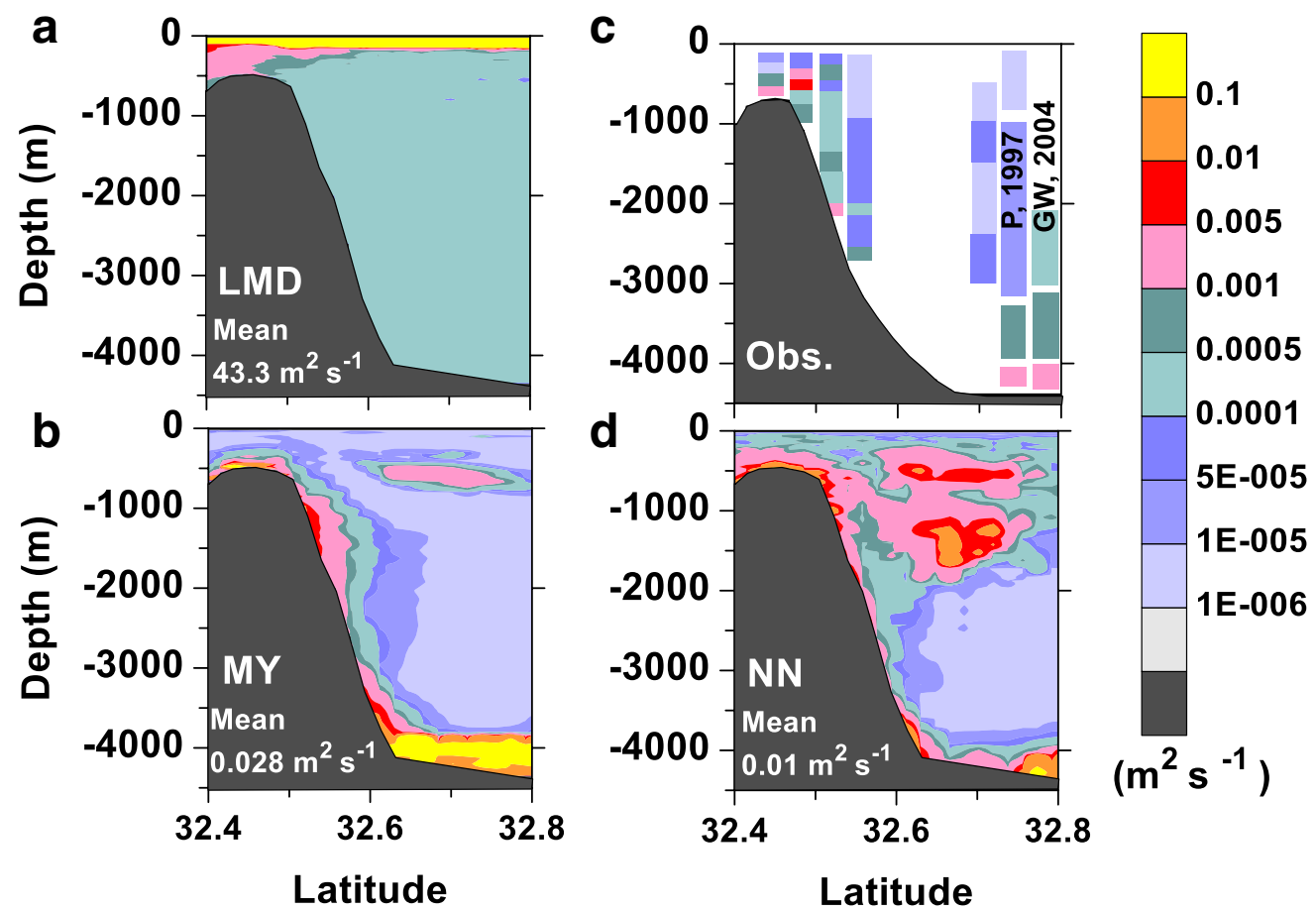

Fig. 6 A transect of the significant vertical temperature diffusivities at $128^{\circ} 41.0^{\prime} \mathrm{W}$ for different vertical mixing parameterizations: a $L M D$, b MY, and d NN. c Observations from Kunze and Toole (1997) and Toole et al. (1997). In c, GW, 2004 refers to the values of Ganachaud and Wunsch (2004) and P, 1997 the observations of Polzin et al. (1997)

for MY, and $0.01 \mathrm{~m}^{2} \mathrm{~s}^{-1}$ for NN. When considering these values, it should be remembered that they are mean significant values and were an average over the "hot spot" of the guyot and not over a large area including many background values. These factors result in much higher values than typically observed, such as $10^{-3}$ or $10^{-4}$ $\mathrm{m}^{2} \mathrm{~s}^{-1}$. LMD had the highest mean of the significant temperature diffusivities with the high values concentrated at the surface. This is significantly different than the mean LMD diffusivities in R06 (Fig. 10 in R06), which had values exceeding $10^{-3} \mathrm{~m}^{2} \mathrm{~s}^{-1}$ below $2500 \mathrm{~m}$ and values in the upper ocean above $1000 \mathrm{~m}$ below $5 \times 10^{-4} \mathrm{~m}^{2} \mathrm{~s}^{-1}$. It should be noted that as the average of the largest $1 / 3$ of the values, this was much higher than the overall mean temperature diffusivity of $0.26 \mathrm{~m}^{2} \mathrm{~s}^{-1}$. The LMD temperature diffusivity values exceeded $5 \times 10^{-3} \mathrm{~m}^{2} \mathrm{~s}^{-1}$ in the upper $150 \mathrm{~m}$ and $10^{-4} \mathrm{~m}^{2} \mathrm{~s}^{-1}$ throughout the entire water column (Fig. 6a). This was much higher than the background values set at $10^{-6} \mathrm{~m}^{2} \mathrm{~s}^{-1}$, which was uniform throughout the domain for all cases. Additionally, with LMD, there was no evidence of enhanced mixing in the area of the diurnal or semidiurnal tidal beams and mixing was not enhanced along the bottom or along the tidal beams. This is much different behavior than LMD vertical diffusivities in R06, where the vertical temperature diffusivities exceeded $0.001 \mathrm{~m}^{2} \mathrm{~s}^{-1}$ below $2500 \mathrm{~m}$. This indicates that the implementation of LMD changed from the earlier version of ROMS.

The mean of the significant temperature diffusivities was much lower with MY, $0.028 \mathrm{~m}^{2} \mathrm{~s}^{-1}$ (the overall mean was $6.0 \times 10^{-4} \mathrm{~m}^{2} \mathrm{~s}^{-1}$ ) (Fig. 6b). Mixing was enhanced along the bottom all along the guyot and basin with extremely high values, $>0.1 \mathrm{~m}^{2} \mathrm{~s}^{-1}$. There was also enhanced mixing in the upper water column away from the guyot roughly in the area of the $K_{1}$ internal tidal beam.

The mean of the significant temperature diffusivities was lowest of the three for $\mathrm{NN}, 0.01 \mathrm{~m}^{2} \mathrm{~s}^{-1}$ (the overall mean was $1.2 \times 10^{-4} \mathrm{~m}^{2} \mathrm{~s}^{-1}$ ) (Fig. 8d). Temperature diffusivities were higher in the upper $2000 \mathrm{~m}$ in large patches, particularly in the area of the $K_{1}$ tidal beam and below the internal tidal beams. Like MY, mixing for $\mathrm{NN}$ was enhanced along the bottom over the guyot, but unlike MY, it was not enhanced over all of the basin and the benthic values were much lower than those of MY.

The distribution of the vertical temperature diffusivities shows clear differences between the three schemes. LMD has two peaks, one around $10^{-4} \mathrm{~m}^{2} \mathrm{~s}^{-1}$ and another very high peak around $10 \mathrm{~m}^{2} \mathrm{~s}^{-1}$, which is extremely high. MY and NN have similar distributions, although MY diverges 

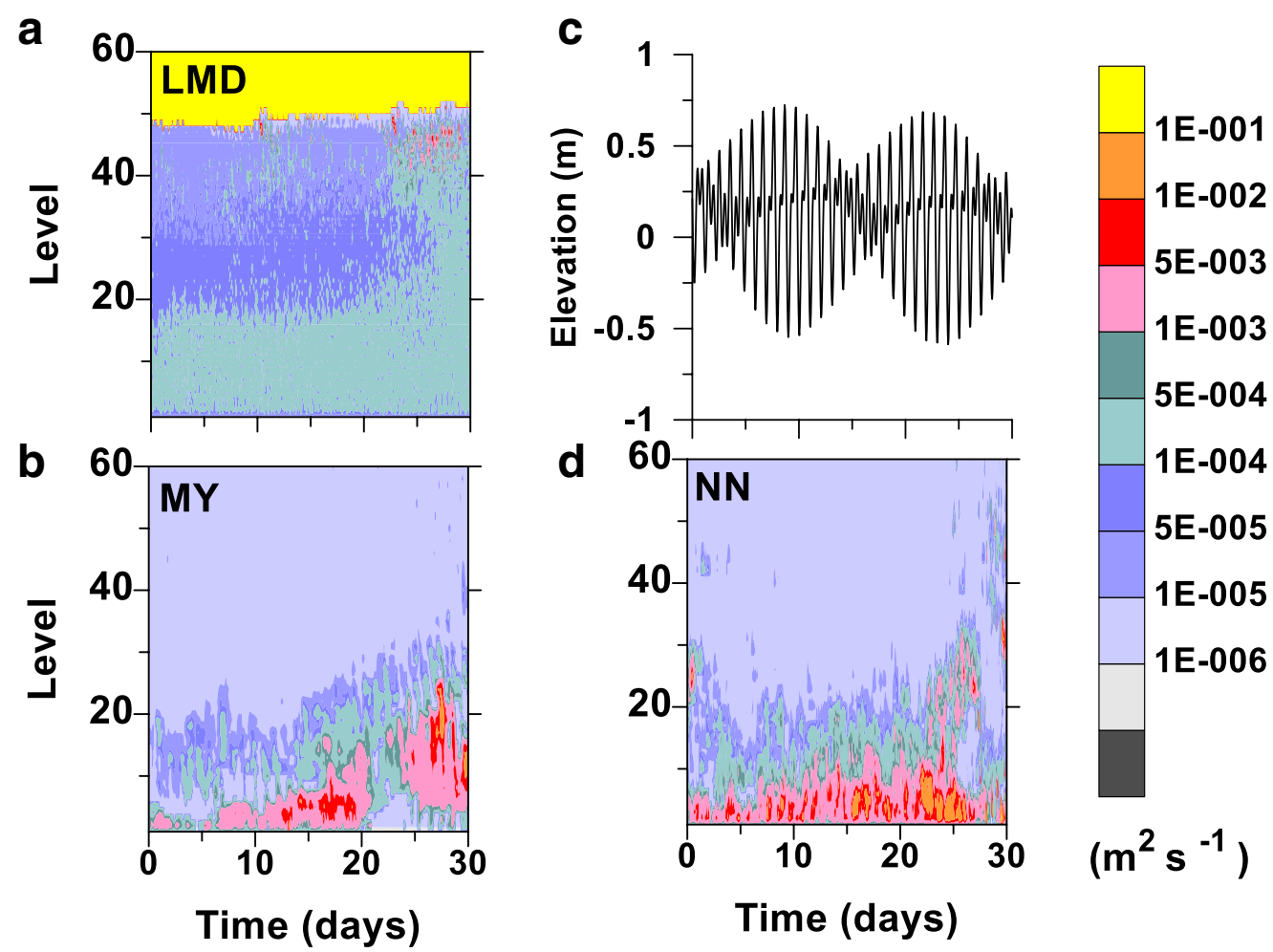

Fig. 7 Time series of the vertical temperature diffusivities over the crest of the guyot using the $\mathbf{a} L M D, \mathbf{b} M Y$, and $\mathbf{d}$ NN vertical mixing parameterizations. $\mathbf{c}$ Time series of the elevations to indicate the daily and spring-neap tidal cycles. From level 1 to 60 , the depths for the rho and horizontal velocities rounded to the nearest $m$ at this location are: 492., 484., 474., 465., 454., 445., 433., 422., 411., 399., 387., 376., 364., 352., 340., 328., 316., 304., 292., 281., 269., 258., 247., 236., 225., 214., 204., 193., 183., 174., 164., 155., 146., 137., 129., 121., 113., 105., 98., 91., 84., 78., 71., 65., 60., 54., 49., 44., 39., 35., 30., 26., 23., 19., 15., 12., 9., 6., 4., and $1 \mathrm{~m}$
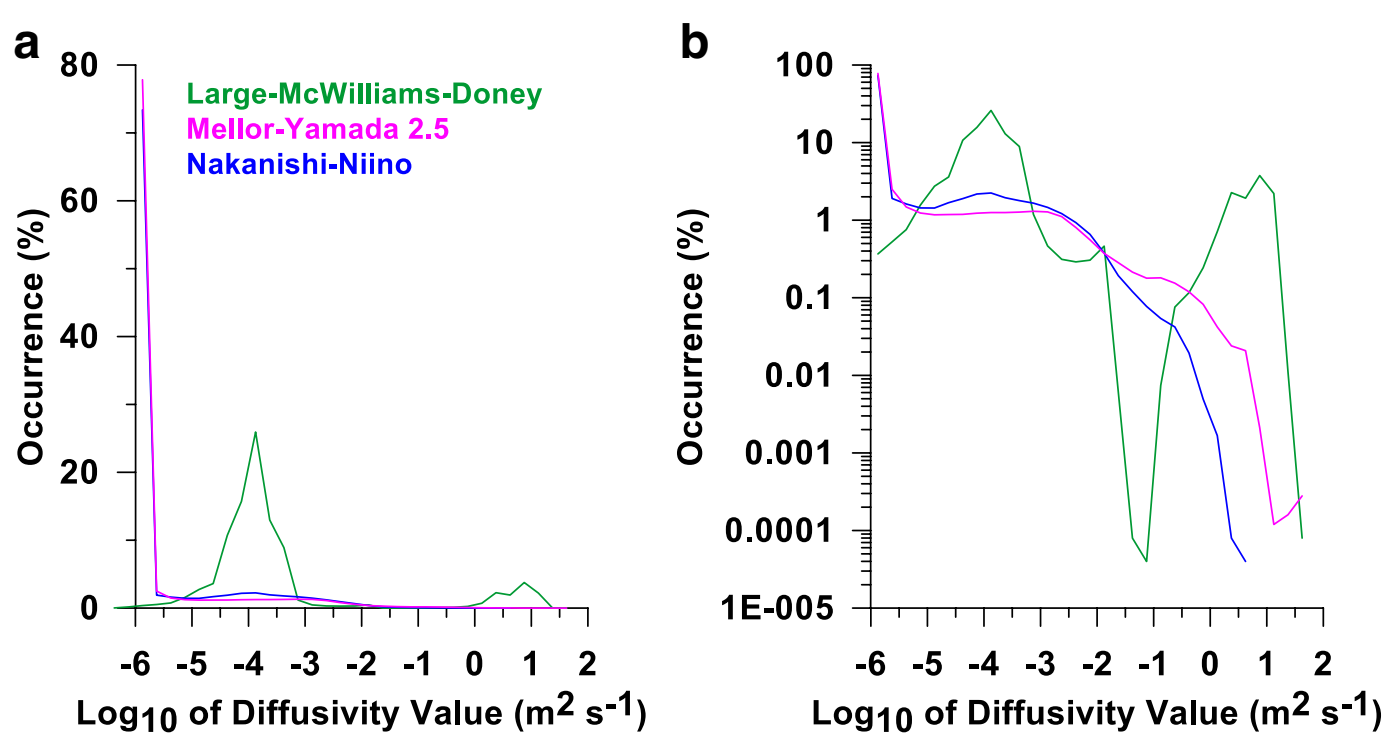

Fig. 8 Probability density distributions of the vertical temperature diffusivities along a North-South transect over the guyot. The values for LMD are given in green, MY in magenta, and NN in blue 
around $10^{-2} \mathrm{~m}^{2} \mathrm{~s}^{-1}$ and extends about one order of magnitude higher. The high MY values occurred near the bottom in the basin (Fig. 6b).

If tidal mixing increases the diffusivities, it seems reasonable that the diffusivities should vary in time peaking when the velocities peak during both the daily and spring-neap cycles. Investigation of time series of the vertical temperature diffusivities showed that LMD did not indicate a significant signature at these frequencies (Fig. 7a). In fact, the major change was a decrease in the diffusivities below level 40 (deeper than $91 \mathrm{~m}$ ) and an increase between levels 40 and $50(24-91 \mathrm{~m})$ after 25 days, just subsequent to a spring tide (Fig. 7c). However, temperature diffusivities from both $\mathrm{MY}$ and $\mathrm{NN}$ fluctuated at the diurnal and semidiurnal frequencies (Fig. 7b, d, respectively). This is most clear in Fig. 7 near the bottom. They also increase after 25 days, just subsequent to the second spring tide, but had no apparent response to the first spring tide (10 days (Fig. 7c)). Spectra of the vertical temperature diffusivities also indicated that they fluctuated with the tidal signals for MY and NN, but for LMD primarily in the basin near the surface at the diurnal frequency (Fig. 9 and Additional file 1: Figures S9, S10). The spectra for MY were whiter, since MY is prone to have spikes of high values, which whiten the spectra. The higher benthic values with MY in the basin are apparent as are the higher values for LMD (Fig. 9).

An important part of this evaluation is a comparison to observations. Fortunately, Kunze and Toole (1997) collected $24 \mathrm{~h}$ time series of microstructure observations, which they converted to density diffusivities (Fig. 9a). As mentioned earlier, care must be taken when comparing the observational values, which do not cover an entire spring-neap tidal cycle, against statistics from model time series, covering two spring-neap tidal cycles. The observations may have been collected during a time of high mixing or a time with a background value; therefore, a mismatch or a high model value may not be incorrect. Comparison of the observational diffusivity values against the model estimates for the significant temperature diffusivities (Fig. 6) showed that the model values were higher than those observed. At first glance, LMD seemed to replicate the diffusivities the best, except in the upper $200 \mathrm{~m}$, where it strongly overmixed. However, it missed the higher mid-water column values in the observations. MY and NN have much stronger midwater column mixing, roughly by an order of magnitude. Compared to the observations, their diffusivities are too high. Again, it should be noted that the observations are averaged over a much shorter time period than the model values and could have been collected at times of low turbulence. As the model time series show the high values occur sporadically, strong mixing events would be easy to

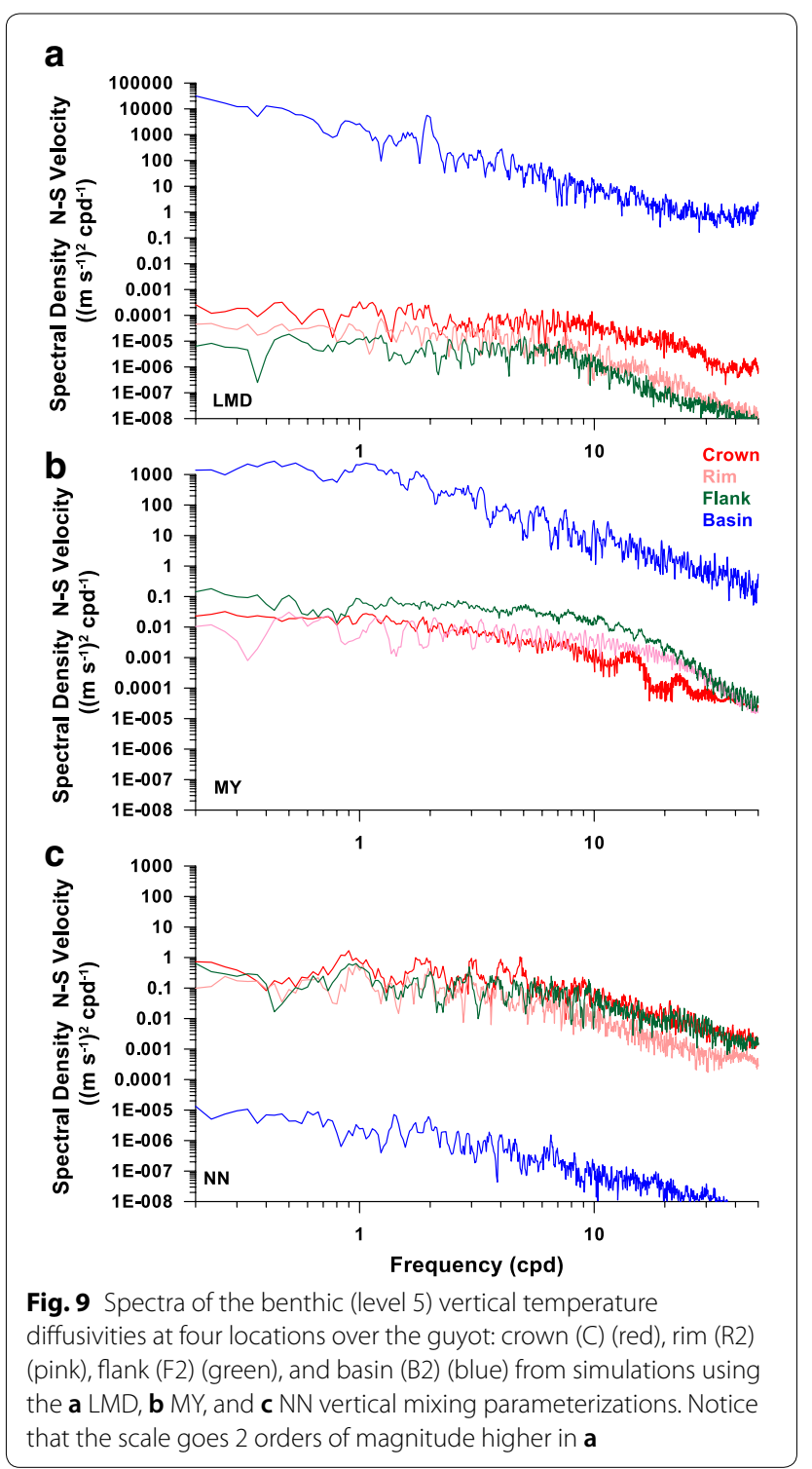

miss. As a result, this comparison is not a definitive criterion, although the model parameterizations appear to overmix.

\section{Effects on the temperature fields}

The widely different vertical diffusivities had widely different effects on the temperature and salinity fields (Fig. 10a-c and Additional file 1: Figure S9a-c, respectively). To better illustrate the differences, the initial temperature (or salinity) field has been subtracted from the average of the last five days to show the temperature (or salinity) changes (Figs. $9 \mathrm{~d}-\mathrm{f}$ and $10 \mathrm{~d}-\mathrm{f}$, respectively). Additionally, to remove spurious mixing due to advection as described by Marchesiello et al. (2009) and to highlight the effects of the vertical mixing 

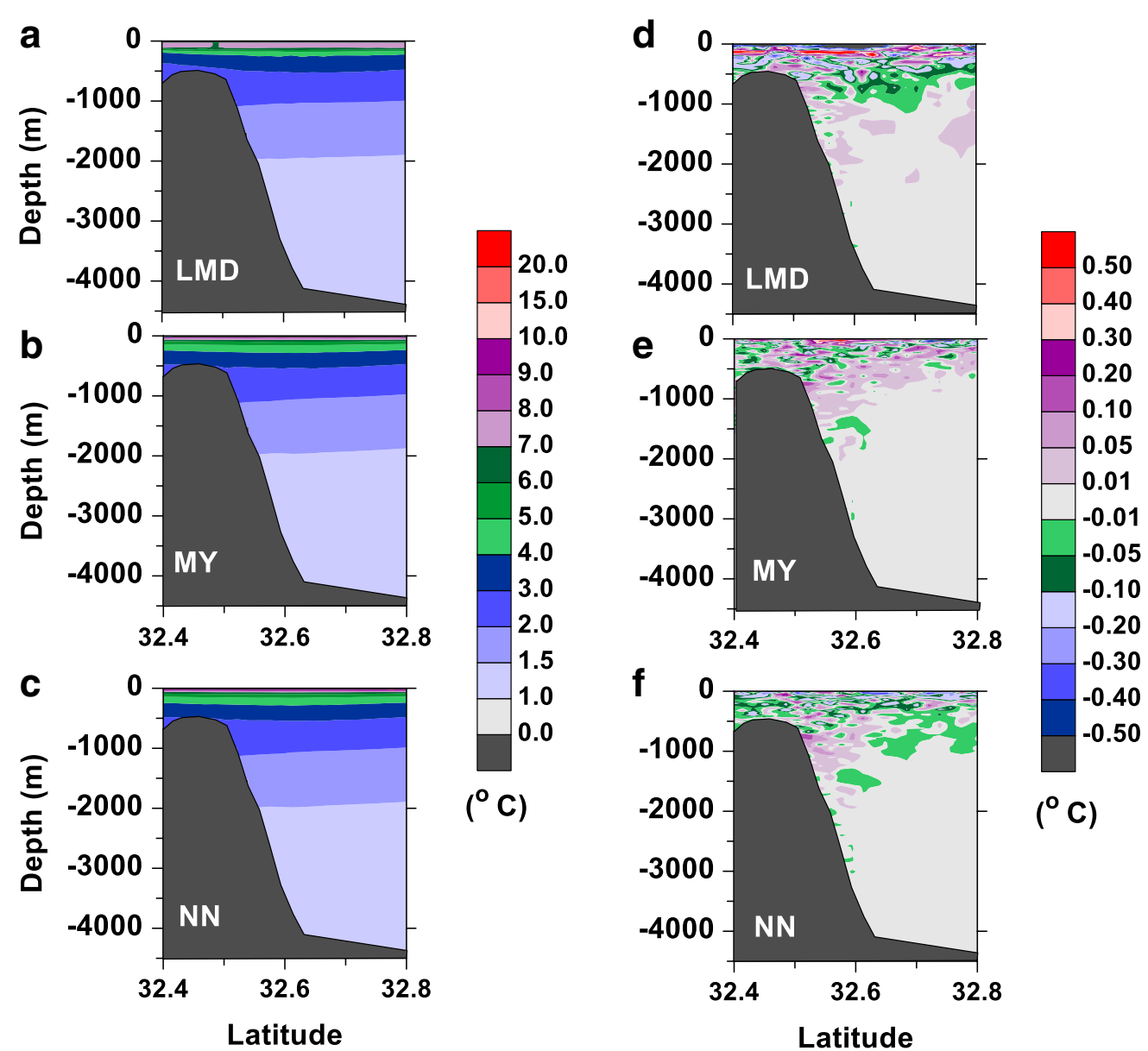

Fig. 10 The a-c potential temperatures average over the last 5 days and the $\mathbf{d}-\mathbf{f}$ difference between those averaged values and the initial values after removing the values associated with advection using the $\mathbf{a}, \mathbf{d} L M D, \mathbf{b}, \mathbf{e} M Y$, and $\mathbf{c}, \mathbf{f}$ NN vertical mixing parameterizations

parameterizations, the temperature differences from a simulation with background levels of vertical mixing were removed from the temperature differences. This simulation included tidal velocities and the associated advection and it is believed that the resulting temperature differences are a good estimate of the spurious temperature differences due to advection identified by Marchesiello et al. (2009). The temperature changes were largest for LMD and MY (Fig. 10d, e), with the largest differences in the upper $500 \mathrm{~m}$, near the pycnocline (Fig. 10a, b). The potential temperature fields are similar for all mixing parameterizations (Fig. 10a-c). The potential temperature changes for all three mixing schemes were highest in the upper $3000 \mathrm{~m}$ and roughly followed the path of the internal tidal beams. Temperature changes for NN were similar to MY (Fig. 11c), with lower magnitudes, roughly a factor of 2 . This is consistent with the lower mean temperature diffusivity. LMD had larger temperature changes in the in the upper $200 \mathrm{~m}$, roughly a factor of 3 higher than NN. Salinity changes were primarily limited to the upper $1000 \mathrm{~m}$, with the largest changes in the upper $200 \mathrm{~m}$ and as opposed to temperature, salinity changed more for NN than for MY in the upper $200 \mathrm{~m}$ (Fig. 11). Again salinity changes associated with the background diffusivity were removed, so these changes are believed to arise from the different vertical mixing parameterizations.

\section{Discussion}

The GLS scheme could not be properly evaluated, since performances for all its three flavors are in doubt. This is different from their behavior in a previous evaluation (R06). The LMD vertical mixing parameterization was found to overmix the water column and was also quite different from that in R06. The values exceeding $0.1 \mathrm{~m}^{2} \mathrm{~s}^{-1}$ are much higher than the mean LMD diffusivities in R06 (Fig. 10 in R06), which had values at the same depth below $5 \times 10^{-4} \mathrm{~m}^{2} \mathrm{~s}^{-1}$. This difference is not attributable to comparing a mean significant diffusivity against a mean diffusivity, as the mean diffusivities 

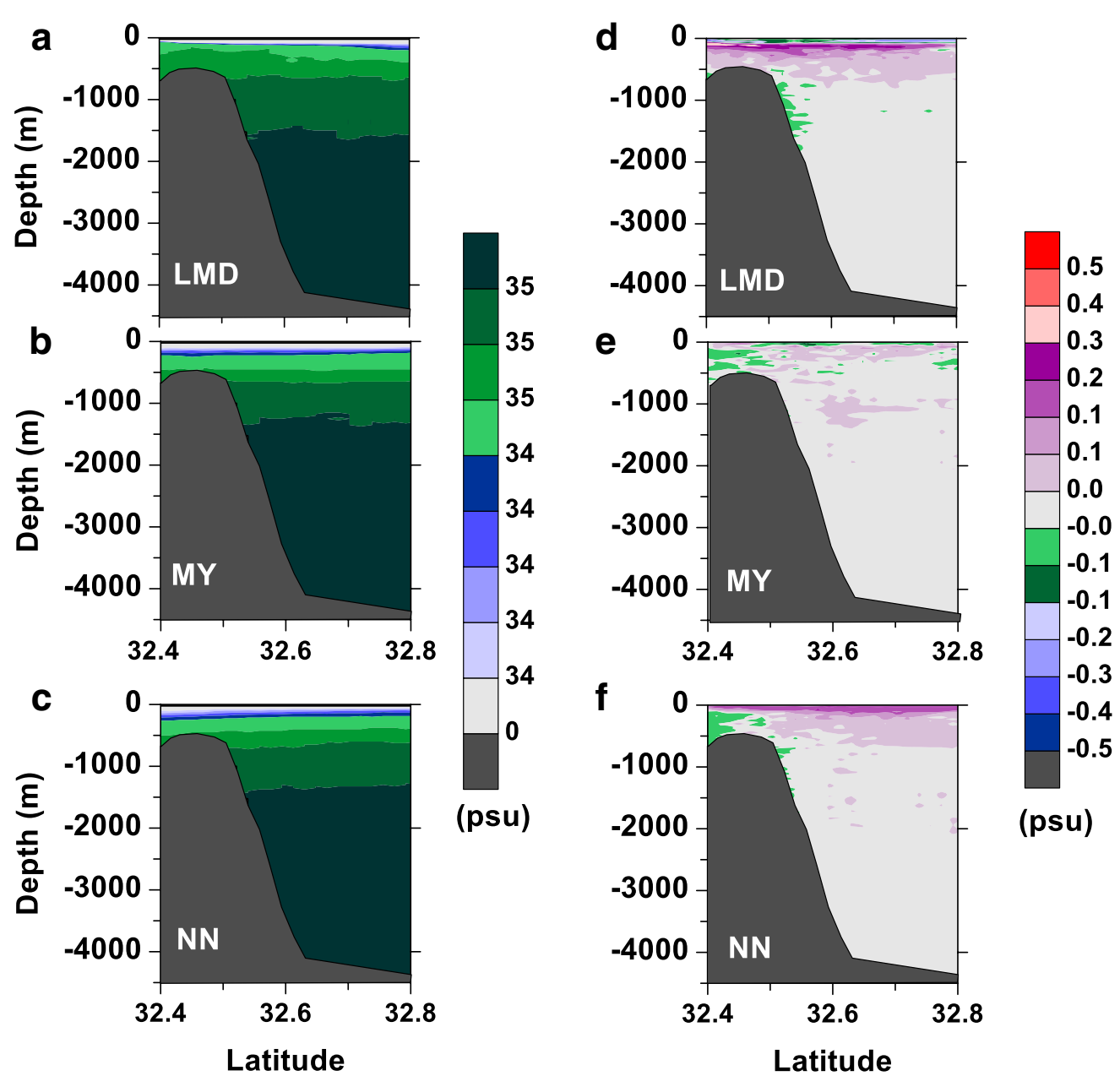

Fig. 11 The $\mathbf{a}-\mathbf{c}$ salinities averaged over the last 5 days and the $\mathbf{d}-\mathbf{f}$ difference between those averaged values and the initial values using the $\mathbf{a}, \mathbf{d}$ $L M D$, $\mathbf{b}$, e $M Y$, and $\mathbf{c}$, $\mathbf{f} N N$ vertical mixing parameterizations

show the same pattern. Additionally, in R06, the highest values occurred below $2500 \mathrm{~m}$, where diffusivities exceeded $10^{-3} \mathrm{~m}^{2} \mathrm{~s}^{-1}$; whereas, in this study, the values below $1000 \mathrm{~m}$ were below $5 \times 10^{-4} \mathrm{~m}^{2} \mathrm{~s}^{-1}$. The response of the LMD scheme between the two versions of ROMS was extremely different, with strong overmixing by LMD in the later version. The difference is not due to an enhanced background diffusivity in the upper ocean, as the background diffusivity was constant over the domain. LMD was also found to overmix for wind-induced mixing (RH17). Therefore, the implementation of LMD and its behavior changed from the previous version of ROMS to this version, particularly the diffusivities. MY temperature diffusivities also looked quite different from R06 to the present simulation. Again, the difference is not attributed to the mean versus the significant values, since the mean values are also different (not shown). Since the input fields and resolution are the same, the differences must lie in changes in the software. Identification of the exact software modifications that caused these changes in the results is better done by the ROMS group that did the modifications than the authors.

As to why the different vertical mixing parameterizations' performances from the same version differ, the basic physics of the methods need to be examined. Since $\mathrm{NN}$ is basically MY with enhance surface mixing, their physics are basically the same. However, their physics differs significantly from those of the LMD scheme. In both MY and NN, the turbulent kinetic energy and a generic length scale are time stepped through the model using horizontal and vertical advection and a diffusivity of the diffusivity coefficient. The turbulent dissipation, turbulent production, shear, and buoyancy production are calculated from these and finally, diffusivity is calculated from the turbulent kinetic energy using Galpernin's stability factors, although there is the Kantha-Clayson option for the momentum stability function. The enhancements of the MY scheme developed by NN 
primarily focus on the surface layer and entail changes in the turbulent length scale and the stability functions. $\mathrm{NN}$ includes buoyance in the length-scale determination, so the length scale decreases as stratification increases. The LMD scheme operates quite differently from MY and NN. It does not calculate or time step the turbulent kinetic energy or turbulent length scale. It basically has three parts: surface boundary layer, bottom boundary layer, and interior mixing. First, the interior mixing is calculated based on three processes: shear instabilities, internal wave breaking, and double diffusion. In our simulations, double diffusion was not implemented. For the surface boundary layer, the depth of the surface boundary layer is determined based on the Richardson number. Within this surface boundary layer, the vertical diffusivities are calculated from the surface forcing and the gradient of the interior diffusivity below the surface mixed layer. The bottom boundary-layer calculations follow the surface procedure, but with current shear against the sea floor replacing the surface forcing and working in the opposite vertical direction.

From this information on the vertical mixing parameterizations, it is clear that LMD method has quite a different approach. LMD has much higher diffusivity values both in the interior and at the surface (Fig. 7). The increases of LMD in the interior must come from the three processes: shear instabilities, wave breaking, and/or double diffusion. Since double diffusion was not implemented in these simulations, it is not the cause. Since the stratification is essentially the same for all simulations (Figs. 10a-c and 11a-c) and the internal wave breaking is based on the stratification, internal wave breaking is not likely to be the source of the many high values; although, it is likely the source of the increased number of values at $10^{-4} \mathrm{~m}^{2} \mathrm{~s}^{-1}$ in Fig. 8b. Consequently, in the interior, the general increased diffusivity for LMD is attributed to the formulation of the shear instabilities in LMD based on the Richardson number versus the calculation of turbulent kinetic energy in MY and NN. The enhanced surface mixing in LMD is attributed to the handling of surface forcing. In comparison to observations for wind mixing, LMD was found to overmix both in the surface and interior (Robertson and Hartlipp 2017), although more comparisons are needed for a definitive evaluation. The higher vertical diffusivities in LMD spread and lower the $K_{1}$ spectral peak (Fig. 5a). Since the seamount is near the $K_{1}$ diurnal critical latitude, the $K_{1}$ tides are impacted more than the semidiurnal tides. The differences between $\mathrm{NN}$ and $\mathrm{MY}$ result from the length-scale formulation and the stability functions. Although these were designed for the surface layer, they are applied to the entire water column and appear to primarily impact the bottom boundary layer (Figs. 6 and 7) and reduce the number of high values in the domain (Fig. 8). The extremely high diffusivities in MY appear at the bottom (Fig. 6). The length scale and stability formulations in $\mathrm{NN}$ reduce the diffusivities in the benthic boundary layer and increase them in the mid-water column (Fig. 6).

Since the physics of NN and MY is similar, it is no surprise that they performed similarly. Since the models tend to overmix and NN mixed less than MY, it is believed that NN is minutely better. Additionally, NN had a slightly lower $\mathrm{rms}$ for $\mathrm{M}_{2}$, less benthic mixing, more mid-water column mixing, and fewer values exceeding $1 \mathrm{~m}^{2} \mathrm{~s}^{-1}$. The overall mean for $\mathrm{NN}$ is lower than that for MY and better matches the canonical value of $10^{-4}$ $\mathrm{m}^{2} \mathrm{~s}^{-1}$ typically used. The lead author also prefers NN, because it spikes less. $\mathrm{NN}$ also performed equivalently as MY for wind-induced mixing, but proved more stable (RH17).

\section{Summary}

Seven vertical mixing parameterizations in ROMS were evaluated for tidal mixing (LMD, MY, NN, and 4 GLS varieties). An additional simulation with only background mixing was performed to estimate spurious mixing due to advection. The GLS option was found to be performing incorrectly. The performances of the other three parameterizations were investigated. Unfortunately, the small observational data set used precluded identifying a clear, definitive best performer. However, MY and NN were found to best replicate the velocity fields and the observed diffusivities. MY overmixed slightly more than NN. NN is slightly preferred by the authors for several reasons: a slightly lower $r m s$ for $\mathrm{M}_{2}$, less benthic mixing, more mid-water column mixing, a mean value closer to what is generally used, and fewer values exceeding $1 \mathrm{~m}^{2} \mathrm{~s}^{-1}$. Additionally, $\mathrm{NN}$ also slightly outperformed MY in a wind-induced mixing study (RH17), However, generally, MY and NN perform roughly equivalently.

This is by no means a definitive evaluation. A better observational data set for comparison is sorely needed. Here, the focus was on tidal mixing; however, when comparing to observational data, other processes, which contribute to mixing, such as wind and solar heating, daily surface convection, eddies, convection, etc., need to be considered and addressed. This makes the situation even more complicated, which is why we focused on tidal mixing.

Furthermore, it is likely that the best performing vertical mixing parametrization may vary with several parameters, including the software version, the primary mixing process(es), and the location, both proximity to features, bottom roughness, and position in the water column. There are strong indications that the models overestimate 
the vertical diffusivities. This leaves plenty of room for improvement in the implementation of vertical mixing parameterizations. New mixing schemes are continually being developed and their performance needs to be evaluated.

\section{Supplementary information}

Supplementary information accompanies this paper at https://doi. org/10.1186/s40562-019-0146-y.

Additional file 1. Supplemental figures and information.

\section{Acknowledgements}

This paper was written at Nanjing University of Information Science and Technology with simulations performed both there, Xiamen University Malaysia, and University of New South Wales Canberra. The analysis was primarily performed at Xiamen University Malaysia. The authors thank Erickson, Kunze, and Toole for providing the observational data used in the study. We also thank the anonymous reviewers for their time and effort in improving our paper.

\section{Authors' contributions}

RR performed the model simulations, analyzed the results, and wrote the paper. CD provided input into the manuscript and provided funding. Both authors read and approved the final manuscript.

\section{Funding}

This project received funding for research and travel from the National Key Research and Development Program of China (2017YFA0604100, 2017YFA0604103), publication fees from a Xiamen University Internal Grant (XMUMRF/2018-C2/ICAM/0003) "Ocean Mixing in Various Conditions and its Handling in the Regional Ocean Modeling System (ROMS) Model" and travel fees for Prof. Robertson from the visiting international scientist program at Nanjing University of Information Science and Technology (NUIST) China. Work performed at University of New South Wales (UNSW) Canberra was not under a grant and Prof. Robertson's affiliation with UNSW Canberra was terminated in 2017.

\section{Availability of data and materials}

The model runs are quite large, too large to be stored on-line. They are available upon request.

\section{Competing interests}

The only known competing interests are of vertical mixing parameterization developers and software developers who may be unhappy with the results.

\section{Author details \\ 'China-ASEAN College of Marine Sciences, Xiamen University Malaysia, Jalan Sunsuria, Bandar Sunsuria, 43900 Sepang, Selangor, Malaysia. ${ }^{2}$ Oceanic Modeling and Observational Laboratory, School of Marine Sciences, Nanjing University of Information Science and Technology, Nanjing 210044, People's Republic of China. ${ }^{3}$ Southern Laboratory of Ocean Science and Engineering (Guangdong Zhuhai), Zhuhai 519000, China.}

Received: 30 August 2019 Accepted: 15 November 2019 Published online: 29 November 2019

\section{References}

Brink KH (1991) Coastal-trapped waves and wind-driven currents over the continental shelf. Ann Rev Fluid Mech 23:399-412. https://doi.org/10.1146/ annurev.fl.23.010191.002133
Brink KH (1995) Tidal and lower frequency currents above Fieberling Guyot. J Geophys Res Oceans 100:10817-10832. https://doi.org/10.1029/95JC0 0998

Durski S, Glenn SM, Haidvogel DB (2004) Vertical mixing schemes in the coastal ocean: comparison of the level 2.5 Mellor-Yamada scheme with an enhanced version of the K profile parameterization. J Geophys Res Oceans 109:C01015. https://doi.org/10.1029/2002jc001702

Egbert GD, Erofeeva S (2002) Efficient inverse modeling of barotropic ocean tides. J Atmos Ocean Technol 19:22475-22502. https://doi. org/10.1029/2003GL019003

Egbert GD, Ray R (2000) Significant dissipation of tidal energy in the deep ocean inferred from satellite altimeter data. Nature 405:775-778. https:// doi.org/10.1038/35015531

Eriksen CC (1991) Observations of amplified flows atop a large seamount. J Geophys Res Oceans 96:15227-15236. https://doi.org/10.1029/91jc01176

Eriksen CC (1998) Internal wave reflection and mixing at Fieberling Guyot. J Geophys Res Oceans 103:2977-2994. https://doi.org/10.1029/97jc03205

Feynmann RP, Leighton RB (1994) Six not so easy pieces. Addison-Wesley Publishing, Boston. ISBN: 978-0201409550

Furuichi N, Hibiya T (2015) Assessment of the upper-ocean mixed layer parameterizations using a large eddy simulation model. J Geophys Res Oceans 120:2350-2369. https://doi.org/10.1002/2014jc010665

Furuichi N, Hibiya T, Niwa Y (2012) Assessment of turbulence closure models for resonant inertial response in the oceanic mixed layer using a large eddy simulation model. J Oceanogr 68:285-294. https://doi.org/10.1007/ s10872-011-0095-3

Ganachaud A, Wunsch C (2004) Improved estimates of global ocean circulation, heat transport and mixing from hydrographic data. Nature 410:240-242. https://doi.org/10.1038/35044048

Garrett C (2003) Internal tides and ocean mixing. Science 301:1858-1859. https://doi.org/10.1126/science.1090002

Holloway PE, Merrifield MA (1999) Internal tide generation by seamounts, ridges, and islands. J Geophys Res 104:25937-25951

Ijichi T, Hibiya T (2015) Frequency-based correction of finescale parameterization of turbulent dissipation in the deep ocean. J Atmos Ocean Technol 32:1526-1535. https://doi.org/10.1175/JTECH-D-15-0031.1

Klymak JM, Legg SM (2010) A simple mixing scheme for models that resolve breaking internal waves. Ocean Model 33:224-234

Koch-Larrouy A, Atmadipoera A, Van Beck P, Madec G, Souhaut M (2015) Estimates of tidal mixing in the Indonesian Archipelago from multidisciplinary INDOMIX in situ data. Deep-Sea Res I 106:136-153. https://doi. org/10.1016/j.dsr.2015.09.007

Kundu PK, Cohen IM, Dowling DR (2015) Fluid mechanics, 6th edn. Academic Press, Cambridge. ISBN-13:978-0124959351

Kunze E, Toole JM (1995) Fine- and microstructure observations of trapped diurnal oscillations atop Fieberling Seamonut. In: Müller P, Henderson D (eds), Topographic effects, in the ocean. Proceedings of Aha Huliko, a Hawaiian winter workshop. School of Ocean and Earth Sci. And Technol., Univ. of Hawaii, Honolulu, pp 15-42

Kunze E, Toole JM (1997) Tidally driven vorticity, diurnal shear, and turbulence atop Fieberling seamount. J Phys Oceanogr 28:811-814. https://doi. org/10.1175/1520-0485(1997)027\%3c2663:TDVDSA\%3e2.0.CO;2

Kunze E, Dower JF, Beveridge I, Dewey R, Bartlett KP (2006) Observations of biologically generated turbulence in a coastal inlet. Science 313:17681770. https://doi.org/10.1136/science.1129378

Large WG, Gent PR (1999) Validation of vertical mixing in an equatorial ocean model using large eddy simulations and observations. J Phys Oceanogr 29:449-464. https://doi.org/10.1175/1520-0485(1999)029\%3c0449:VOVMI A\%3e2.0.CO;2

Ledwell JR, Watson AJ, Law CS (1998) Mixing of a tracer released in the pycnocline. J Geophys Res Oceans 103:21499-21529. https://doi. org/10.1029/98JC01738

Li M, Zhong L, Boicourt WC (2005) Simulations of Chesapeake Bay estuary: sensitivity to turbulence mixing parameterizations and comparison with observations. J Geophys Res Oceans 110:C12004. https://doi. org/10.1029/2004JC002585 
Marchesiello P, Debreu L, Couvelard X (2009) Spurious diapycnal mixing in terrain-following coordinate models: the problem and a solution. Ocean Model 26:156-169. https://doi.org/10.1016/j.ocemod.2008.09.004

Mellor GL, Yamada T (1982) Development of a turbulence closure model for geophysical fluid problems. Rev Geophys Space Phys 20:851-875. https ://doi.org/10.1029/RG020i004p00851

Merrifield MA, Holloway PE (2002) Model estimates of $\mathrm{M}_{2}$ internal tide energetics at the Hawaiian Ridge. J Geophys Res. https://doi.org/10.1029/2001J C000996

Munk W, Wunsch C (1998) The moon and mixing: abyssal recipes II. Deep-Sea Res 45:1977-2010. https://doi.org/10.1016/S0967-0637(98)00070-3

Nagai T, Hibiya T (2015) Internal tides and associated vertical mixing in the Indonesian Archipelago. J Geophys Res 120:3373-3390. https://doi. org/10.1002/2014JC010592

Nakanishi M, Niino H (2009) Development of an improved turbulence closure model for the atmospheric boundary layer. J Meteorol Soc Jpn 87:895-912. https://doi.org/10.1029/94JC02257

Naveira-Garabato AC, Polzin KL, Heywood KJ, Visbeck M (2004) Widespread intense turbulent mixing in the Southern Ocean. Science 303:210-214. https://doi.org/10.1126/science.1090929

Nikurashin M, Ferrari R (2011) Global energy conversion rate from geostrophic flows into internal lee waves in the deep ocean. Geophys Res Lett 28:9610. https://doi.org/10.1029/2011gl046576

Petruncio ET (1996) Observations and modeling of the internal tide in a submarine canyon, PhD dissertation for Naval Postgraduate School, Monterey, California

Polzin KL, Toolem JM, Ledwell JR, Schmitt RW (1997) Spatial variability of turbulent mixing in the abyssal ocean. Science 276:93-96. https://doi. org/10.1126/science.276.5309.93

Robertson R (2005) Barotropic and baroclinic tides in the Ross Sea. Antarct Sci 17:107-120. https://doi.org/10.1017/S0954102005002506

Robertson R (2006) Modeling internal tides over Fieberling Guyot: resolution. Parameter Perform Ocean Dyn. https://doi.org/10.1007/s1023 6-006-0062-5
Robertson R, Hartlipp P (2017) Surface wind mixing in the Regional Ocean Modeling System (ROMS). Geosci Lett. https://doi.org/10.1186/s4056 2-017-0090-7

Robertson R, Dong J, Hartlipp P (2017) Diurnal critical latitude and the latitude dependence of internal tides, internal waves and mixing. J Geophys Res Oceans. https://doi.org/10.1002/2016jc012591

Shchepetkin A, McWilliams JC (2004) The regional oceanic modeling system (ROMS): a split-explicit, free-surface, topographic-following-coordinate oceanic model. Ocean Model 9:347-404. https://doi.org/10.1016/j.ocemo d.2004.08.002

St. Laurent LC, Simmons HL, Jayne S (2002) Estimating tidally driven mixing in the deep ocean. Geophys Res Lett. https://doi.org/10.1029/2002GL0156 33

Timmermann R, Beckmann A (2004) Parameterization of vertical mixing in the Weddell Sea. Ocean Model 6:83-100. https://doi.org/10.1016/S1463 $-5003(02) 00061-6$

Toole JM, Schmitt RW, Polzin KL (1997) Near-boundary mixing above the flanks of a mid-latitude seamount. J Geophys Res Oceans 102:947-959. https:// doi.org/10.1029/96JC03160

Umlauf L, Burchard H (2003) A generic length-scale equation for geophysical turbulence. J Marine Res 61:235-265. https://doi.org/10.1357/00222 4003322005087

Umlauf L, Burchard H, Hutter K (2003) Extending the $\mathrm{K}$ - $\omega$ turbulence model toward oceanic applications. Ocean Model 5:195-218. https://doi. org/10.1016/S1463-5003(02)00039-2

Warner JC, Sherwood CR, Arango HG, Butman B, Signell RP (2005) Performance of four turbulence closure methods implemented using a generic length scale method. Ocean Model 8:81-113. https://doi.org/10.1016/j.ocemo d.2003.12.003

\section{Publisher's Note}

Springer Nature remains neutral with regard to jurisdictional claims in published maps and institutional affiliations.

\section{Submit your manuscript to a SpringerOpen ${ }^{\circ}$ journal and benefit from:}

- Convenient online submission

- Rigorous peer review

- Open access: articles freely available online

- High visibility within the field

- Retaining the copyright to your article

Submit your next manuscript at $\boldsymbol{\nabla}$ springeropen.com 